\title{
Remnant of the Past?
}

\section{An Investigation into the Past, Present \\ and Future Role}

of Archaeology in New Zealand Museums

\section{Brenden Shirley}

A Thesis Submitted to the Museum and Heritage Studies Programme Victoria University of Wellington in Partial Fulfilment of the Requirements for the Degree of Master of Museum and Heritage Studies

Victoria University of Wellington

2015 


\section{Abstract}

Museum archaeology is a subject that has received little attention from local academics and museum professionals. This is despite the fact that it continues to be perceived as a foreign subject that most New Zealanders find difficult to relate to. This dissertation takes an exploratory approach in understanding what has to be considered in future efforts to connect museums and their wider communities with archaeology. Rather than reiterating what the literature has previously confirmed, this research examines the perspective of archaeological interpreters, namely museum and heritage professionals. This provides an avenue for examining how archaeological content is perceived by museums, how this can be conveyed to the public and its potential benefits and limitations.

This research was developed around a qualitative methodology that collated data from interviews with practitioners from a range of backgrounds: archaeologists, museum curators, heritage site mangers and Maori studies. An examination of some of the educational programs and resources currently provided by New Zealand museums and heritage sites was undertaken to recognise opportunities already established. A critical observation of exhibition practice provided additional insight into the physical context of archaeological interpretation and display methods.

Key findings from this research found that many of the issues and opportunities are interrelated and not always exclusive to archaeology. Museums are continuing to move away from specialised curation and instead, favouring the development of multidisciplinary, thematic narratives. As a result, they now rely on the support of outside institutions and consultants to provide this perspective. The dissertation concludes by arguing for a multidisciplinary framework where subjects like archaeology recognise the museum's potential as a hub for providing relatable experiences across the various disciplinary perspectives available and as an opportunity to promote and the wider exploration of cultural landscapes in their region. This research makes a contribution to the academic analysis of museum and archaeology in New Zealand by encouraging a more inclusive dialogue around the role museums can play in the future of public archaeology. Engagement within the wider heritage and indigenous communities is required to establish a greater level of cultural agency and awareness for these issues and allows for further involvement in site management and cultural interpretations This can ultimately produce a more personal connection and understanding of archaeology in general. 


\section{Acknowledgements}

First of all I would like to thank my supervisors, Conal McCarthy and David Butts for all their time and guidance throughout the year. Your insightful and constructive advice encouraged me to explore avenues I may otherwise not have considered and this dissertation would not be the same without it.

My sincere thanks to all those who took time out of their busy schedules to be interviewed and share their thoughts and feelings with me. These were an invaluable source of information and have had a profound impact on the outcome of this research. Particular mention must go to Glen Skipper for facilitating my visit to Puke Ariki and to Janet Davidson for making the trip to Wellington. It was much appreciated.

To my fellow inmates in OK 302; Alice and Penny, for their always cheerful company while writing as well as for tagging along on my countless trips to get coffee. You guys are awesome.

And finally to my parents, for their constant support and confidence in me over the course of this degree. More than anything else, this has kept me going during these last two years and I could not have done it without you. 


\section{Table of Contents}

Introduction .......................................................................................................................

Literature ReviewThe Historical Development of Museum Archaeology ....................................... 8

The Public Perception of Archaeology .................................................................................. 9

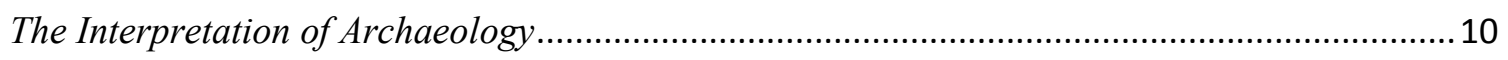

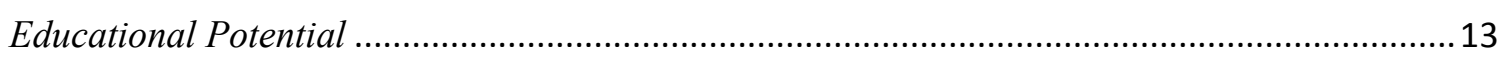

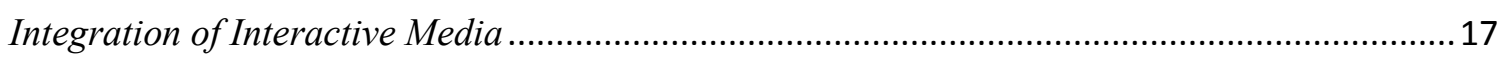

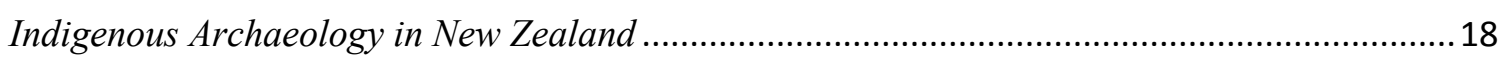

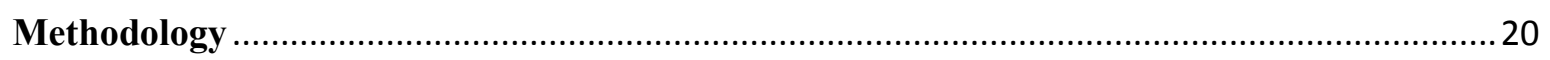

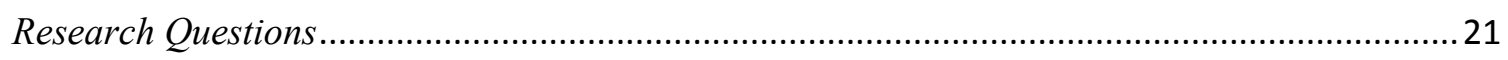

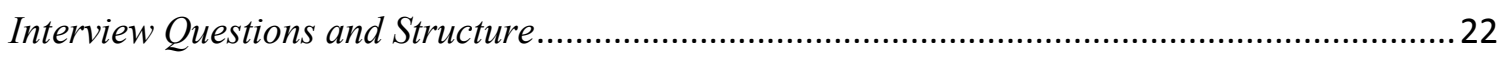

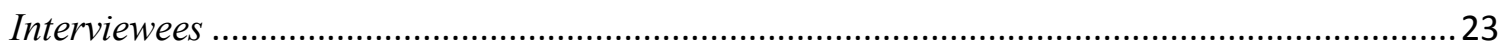

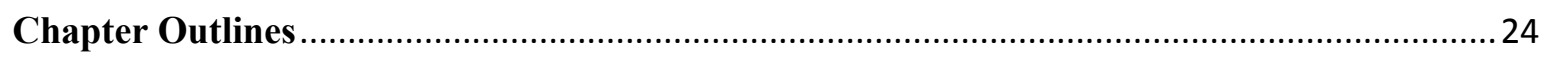

\section{Chapter 1}

Background Context: The Changing Face of Museum Archaeology ............25

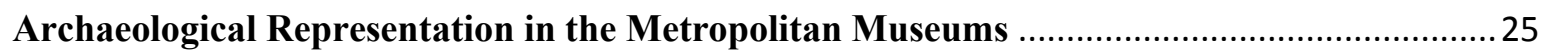

Museum of New Zealand, Te Papa Tongarewa ....................................................................2 25

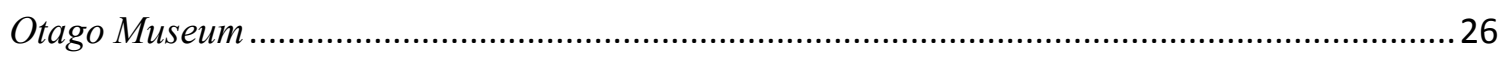

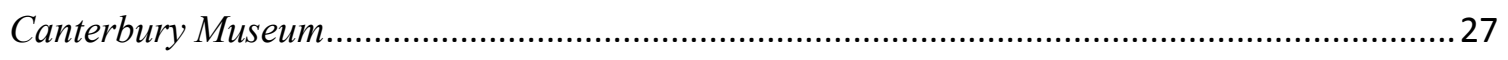

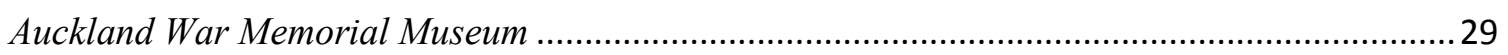

The New Zealand Archaeological Association (NZAA) .......................................................29

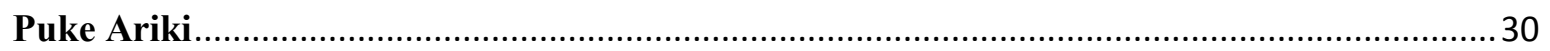

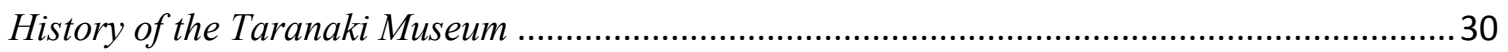

Critical Observations of Archaeological Content at Puke Ariki ...............................................32

\section{Chapter 2}

Interviews: A Hub for Future Exploration ....................................................41 


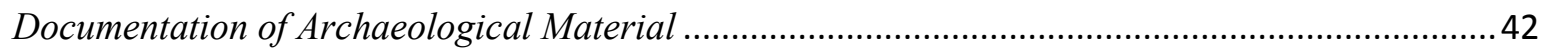

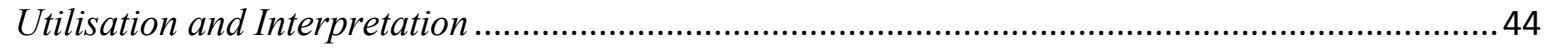

The Relationship between Maori and Archaeology .................................................................... 46

Relationship between Archaeological Sites and Museums ......................................................... 48

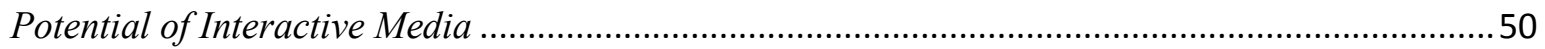

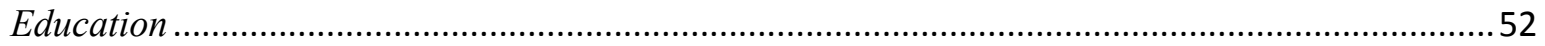

\section{Chapter 3}

Analysis and Discussion: Taking the Museum into the Landscape

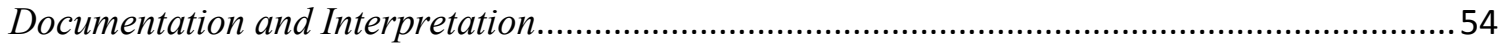

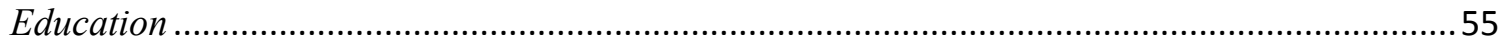

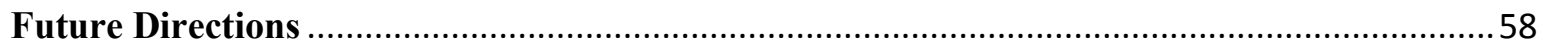

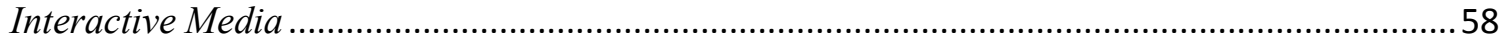

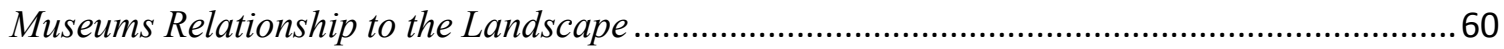

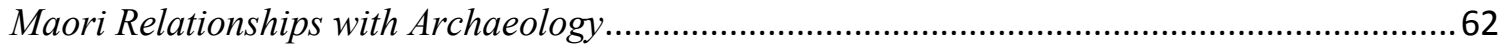

Conclusion: Working Towards Multiple Horizons ..........................................65

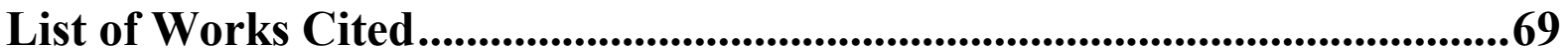

Appendices .................................................................Error! Bookmark not defined. Appendix I: Interview Questions.................................................. Error! Bookmark not defined. Appendix II: Particular Aspects of Museum/ Heritage Site Displays ........... Error! Bookmark not defined. 


\section{List of Figures}

Figure 1 - Omata Stockade display based on material from Nigel Prickett's fieldwork. Social History Gallery: Puke Ariki .35

Figure 2 - Display case presenting a series of artefacts from the Omata Stockade Excavation. Social History Gallery: Puke Ariki 35

Figure 3- Places of Significance Panel including aerial photographs and illustrations of local archaeological sites. Maori Gallery: Puke Ariki. .36

Figure 4 -Moa bones in oven display. Maori Gallery: Puke Ariki .36

Figure 5 -Adze (Toki) display. Maori Gallery: Puke Ariki .37

Figure 6 - Hei Tiki showing burn marks caused during heating process. Maori Gallery: Puke Ariki 37

Figure 7 - Interactive touch screen display for local Pa Sites. Maori Gallery: Puke Ariki.....38

Figure 8 - Moa skeleton display based on material from Richard Cassel's fieldwork. Natural History Gallery: Puke Ariki .38

Figure 9- Model Pa. Education Department: Puke Ariki. 39

Figure 10- Detailed View of model Pa. Education Department: Puke Ariki .39 


\section{Introduction}

One of the most memorable experiences from my undergraduate degree in archaeology was the three week field school I attended in the eastern Bay of Plenty. This involved surveying and excavating a headland pa site which was part of a settlement area established along the coast which had multiple uses across several generations. Whilst the excavation itself was certainly an amazing experience, what really stuck with me was the extent to which the local iwi were involved. As the local marae hosted us and provided our meals and accommodation, we quickly became part of the community. Everyone was always interested in what we were doing and locals frequently came up to the site to visit. Two of the local girls were particularly interested in a career in archaeology and so were invited to join in the daily training exercises and fieldwork alongside the rest of the class. At the end of the three weeks, the lecturers gave a presentation at the marae that summarised their initial findings, how this

related to other sites in the area and what this contributed to the local whakapapa. At the time, this seemed to me like the obvious and appropriate outcome for this project given the close relationship we had established. However as I later learnt, this level of reciprocal understanding is quite rare. In most instances, local communities are left with only a superficial knowledge of what archaeology is and what it seeks to achieve.

As I thought about this some more, I realised that archaeology as understood by the vast majority of the New Zealand public is still a foreign concept. I don't know how many people, after hearing that I studied archaeology, told me that I would have to go to Europe as there isn't enough history in New Zealand. It seems people are quick to equate archaeology with ancient people in a distant land and do not perceive it as holding any relevance or contribution to their own heritage.

Given this situation, I believe further research on public attitudes and understanding of archaeology would hold little value. The research context for this study examined literature across the fields of both museum studies and archaeology focusing primarily on the public's understanding of archaeology and the past as influenced by museums. However, little critical analysis has been done on these issues that incorporates the perspective of museum staff, 
stakeholders and indigenous communities. This study seeks to address the potential of utilising new approaches to develop the public's enthusiastic, but generally misinformed, interest in archaeology. This dissertation argues that this can be achieved by identifying and harnessing underutilised opportunities for archaeological education and outreach available within museums and their wider communities. The need for better education around our unique cultural heritage and prehistory is particularly important for allowing the New Zealand public to develop an appropriate perception of archaeology. This issue must be addressed before any meaningful impact can be achieved.

Museum professionals are the primary focus of this research and it is hoped that this work will provide them with a clearer understanding of the challenges that need to be considered when dealing with archaeological content. This can provide additional benefits for museum visitors in providing them with a wide range of new experiences and perspectives that encourages them to consider how New Zealand archaeology can relate to them. As archaeology is primarily a publicly funded venture, this impact could feed back into the sector in the form of greater support and funding for future endeavours.

\section{Literature Review}

\section{The Historical Development of Museum Archaeology}

Although the modern discipline only developed during the $19^{\text {th }}$ century, archaeology has been an important element of museums for centuries museums are still regarded by the public as the best place to learn about the past (Barker 2010, 294). This is despite the fact that most archaeological collections were not built up for this purpose, but rather as the by-product of antiquarian research. During this period, archaeologists perceived their role as the interpreters of the quality and significance of this material and considered its presentation to the public as a secondary service for the social betterment of the masses (Barker 2010, 295).

Until recently, archaeologists believed in the intrinsic nature of artefacts, that meaning was inbuilt and interpretable from physical descriptions and could otherwise speak for themselves. The visitor's role was purely to appreciate the material in front of them and no further interpretation was deemed necessary (Benton and Watson 2010,130). Over time as racial, political and gender issues began to receive greater attention, museums began to reexamine the way in which their content was being interpreted. This challenged this position and encouraged the public to become more self-aware and involved in their own learning. 
Museums feared that catering to the public's whims regarding how artefacts were displayed, would undermine the true goals of archaeological research and collection management. Tim Benton and Nicola Watson argue that over time, reluctance to fully embrace this shift created a distance between the public and the content. Although archaeological material was still being added to collections, it was not being utilized to its full potential and the presence of archaeology gradually began to fade from the public consciousness (Benton and Watson $2010,133)$.

\section{The Public Perception of Archaeology}

Public education quickly became one of the most important developments for modern museums. It required a major change in perspective, "from passive repositories to active arbiters and interpreters of the past" (Barker 2010, 295). However, the extent to which museums were effectively presenting and explaining archaeological material varied. Ramos and Duganne's survey on the public perception of archaeology in America found that although $88 \%$ of people said they had visited a museum with archaeological material, only $9 \%$ said that this was where they had gained their archaeological understanding (Ramos and Duganne 2000, 12).

This gradual loss of prominence has led to what Nick Merriman has called the 'crisis of representation' (Merriman 2000a, 300). The public, lacking access or engagement to an official representation of archaeology, are forced to create their own understanding based upon a range of myths and preconceptions gathered from alternative sources. Since museums have not challenged these myths, they have been allowed to seep further into the public consciousness.

Archaeology's decision to distance itself from the perception of cowboy treasure hunters and become recognised as a serious discipline removed many opportunities for amateurs to be engaged. Merriman believes archaeology is its own worst enemy in this regard and this only reinforced the idea of archaeology as something reserved for the academic elite. The rapid influx of representations in television, film and the internet has only exacerbated the problem and made it increasingly difficult for the public to establish a cohesive picture of archaeology with the term now associated with everything from dinosaurs to spacemen (Merriman 2000a, 301). Merriman suggests that for museum archaeology to remain relevant, it needs to emphasise the different ways, both academic and public, that 
people can form connections with the content and its wider social context (Merriman 2000b, 108).

A similar situation can be found in New Zealand. In his 1995 survey, Simon Hodge found that although the general public believed archaeology was an important discipline that warranted support, they had little to no idea of what was actually involved and struggled to identify any New Zealand archaeological sites. Hodge attributed this to a lack of communication and outreach by the institutions which failed to ensure their content and message was reaching the public (Hodge, 1995, 270).

Debates over why the New Zealand public have developed a largely international perspective of archaeology and the past in general have been widespread. Fung and Allen have suggested the public have developed a selective recollection based on socially accepted ideas and emotions confined to a specific time and place. These have been reinforced over generations and assimilated into the public consciousness, regardless of whether they remain accurate or not. Fung and Allen interpreted this as a reflection of the nostalgic inertia and reluctance in our society to address the past as anything other than a simpler, positive and romantisced time (Fung and Allen 1984, 211).

It is therefore not surprising that this misconception of the past has translated into a similar perception of New Zealand archaeology. The public has continued to make ill-fated attempts at trying to find connections to a euro-centric notion of the past which in reality, was never there to begin with (Fung and Allen 1984, 214). The public, as a whole, has been

highly effective in ignoring or seemingly forgetting certain connections and associations, particularly concerning the intertwined nature of European and Maori cultural history. It is this malleability of the past and adherence to an outdated framework that Fung and Allen argue, has resulted in the public's inability to recognise the archaeology we do have and instead continued to identify with monumental archaeology that we do not (Fung and Allen 1984, 214).

\section{The Interpretation of Archaeology}

Hedley Swain notes in his opening chapter to An Introduction to Museum Archaeology that the fundamental problem with museum archaeology is that what archaeologists do and what museums do, are often completely different. Furthermore, the sheer range of content 
archaeology covers makes it difficult to condense into a clearly structured exhibit (Swain 2007, 4). Swain feels such exhibits often fail to explain to audiences the lack of definitive answers archaeology can provide. By presenting an open ended interpretation which can, and should, be questioned allows for a greater level of public participation and co-operation (Swain 2007, 10).

For some critics, museum archaeology can only say so much. Susan Vogel notes that "the fact that museums recontextualise and interpret objects is a given, and requires no apologies. Instead, museums should allow the public to know that museums are not a broad frame through which the art and culture of the world can be inspected, but a tightly focused lens that shows the visitor a particular point of view" (Vogel 1991,in Barker 2010, 298). This point echoes Swain's emphasis on the value of archaeological context. The simple act of removing artefacts from a site and placing them in a museum display not only removes their connections and association with other items, but with the cultural landscape in which they are an intrinsic part. Whilst these connections may still be recognised by trained archaeologists, the general public do not have this insight and the items by themselves have limited value (Swain 2007, 4). One of the great ironies of archaeology is although it is a discipline that strives to understand the people of the past, opportunities to present personal stories are rare and typically require a great deal of creativity and imagination to make successful (Swain 2007, 10).

Museum displays and audience engagement has traditionally focused on presenting content in one of two ways, either as objects or ideas. It is now commonly recognised that museum displays with the most impact are those which combine the two. Two crucial dimensions; wonder and resonance, serve in stopping the viewer in their tracks to admire the visual presentation, but also recognise the larger world view and cultural context (Greenblatt 1991 in Barker 2010, 296). Swain suggests the difficulty of interpretation stems from the fact that as a multidisciplinary subject, archaeology doesn't present a concrete identity of its own. This concealment amongst other disciplines, as well as the mixing of different terminology between countries, makes understanding the core concepts of archaeology more difficult for the public to grasp (Swain 2007, 11).

\section{Archaeological Theory}


The difficulty of interpretation is only compounded by the fact that archaeologists themselves have had great difficulty in agreeing on exactly how this should be done. One of the major debates that helped establish the modern era of archaeological thought centred around what is known as the processual approach(Shanks and Hodder, 1995, 1). This presented archaeology as a scientific process to be explained and examined across cultural trends and to be compared in terms of natural and social processes. (Shanks and Hodder, 1995, 1). In doing this, it was hoped it would be easier to gather timeless and value free knowledge neutral to the politics of the era (Shanks and Hodder, 1995, 2). The post-processual reaction to this approach challenged this approach and questioned the forms of knowledge that were appropriate to the social sciences. In essence, the post proccesual approach promoted the subjective influence of particular historical eras as a way of supporting the concept of multiple pasts which co exist and overlap each other (Shanks and Hodder, 1995, 4).

Others, such as John Bintliff, have argued that neither approach serves as a successful interpretive framework and that post processulaism ultimately only posed critical questions without providing any answers or alternative solutions (Bintliff 1993, 93). Bintliff also criticised post proccesualism as being inconsistent and even futile, in that it established a rigid framework within a relativistic and fluid approach which is caught up in so many interpretations that it loses sight of what it was originally trying to achieve (Bintliff 1993, 93).

Another interpretation, by Shanks and Tilley, defines archaeology as a "fourfold hermeneutic" that focuses on four levels of interpretation and on understanding the divisive relationships between them. These include the division between the past and present; the division between understanding other societies and cultures; the division between contemporary society's impact on site interpretation compared to its original purpose and value and the divisions between the different communities that are involved in the final published conclusions. Shanks and Tilley argue that as these four categories require not only translation between different contemporary cultural and social groups, but also translation across worlds separated by time and space, an attempt to try and fuse these into a single narrative is unrealistic(Shanks and Hodder, 1995, 9). Furthermore, they argue that whilst reestablishing context is arbitrary and cannot reconstruct past symbolism, there are still fundamental processes that determine what artefacts physically can and cannot do which would produce physical evidence which could logically be found if certain scenarios had occurred(Shanks and Hodder, 1995, 15). 
Today, the nature of interpretive archaeology has evolved into one that brings together the two seemingly opposite lines of thought; the "factual" scientific information with the creative imagery and multiple pasts to establish fully realised narratives. It has been argued by Shanks and Hodder, that ultimately all archaeology is interpretive and never comes with an established context and always requires some form of human interaction (Shanks and Hodder, 1995, 31).

\section{Educational Potential}

The educational potential of archaeology has been extensively studied in recent years and has produced a wide range of applicable literature. A common criticism is that too often educators assume the public require straight definitions and outlines of the past, without actually getting their input (Franklin and Moe 2012, 571). This can be seen as a gradual shift over time from the museum agenda, with an emphasis on teaching, to the visitor agenda which emphasises how people learn and make meaning (Moussouri 2014, 12). This new agenda encourages the co-creation of knowledge and provides the public with an opportunity to shape their own learning. By encouraging the public to share information and skills largely based upon intuition and personal experiences can help establish more valuable results and a sense of public ownership (Moussouri 2014, 13).

Kevin Bartoy suggests that the goal of archaeological education should not be to simply teach people about archaeology for its own means, but to teach through the assistance of archaeology as a way of understanding greater topics and themes. This is a crucial distinction which separates the educational content provided to the public from the content provided for archaeologists. Encouraging a wider perspective is recognised as an important way of providing what Bartoy calls a 'hands on, minds on approach' (Bartoy 2012, 554). Enquiry based learning takes a similar approach and is designed to provide students with insight into the multi-disciplinary nature of academic work and how this can impact the nature of the questions being asked (Debert 2014, 82). The key emphasis is both cases is to understand and recognise the value of the different sources of potential information that are available(McDonald 2014, 77).

As previously mentioned, the process of archaeology and what it involves, is an aspect missing from most representations of the subject. However, this is slowly changing 
and has proven beneficial for communities where such projects have been instigated. The Swedish Museum of National Antiquities for example, aimed to get people thinking about different levels of the interpretation process. To illustrate the irregularity of archaeological finds and the difficulty of establishing a common theme, the museum asked visitors to place random objects in a future memories exhibition(Wahlgren and Svanberg 2008, 250).This collection of items was then buried in a pit and visitors were asked to consider how this material would be interpreted by future generations and what significance and meaning they may take from it. This encouraged visitors to consider the nature of the material museums collect, how it is important and why (Wahlgren and Svanberg 2008, 243).

A similar project, within a house museum in Massachusetts, also focused on providing visitors with a first-hand experience of the various facets of archaeological practice (Chan 2011, 169). Its purpose was to ensure the public were aware that archaeological sites were a non-renewable resource and explain that aside from causing irreversible damage to a site, excavations are expensive and resource heavy events, which must have sufficient justification for going ahead (Chan 2011, 181). As the site was also a house museum, it contained a wide variety of material types. This allowed the public to examine the range of ways in which artefacts can be read and that understanding their connection to the larger context of a site, can help forma coherent picture of its unique heritage value(Chan 2011, 187).

Another interesting example is this respect, is that of Colonial Williamsburg. Colonial Williamsburg is the reconstructed capital of the colony of Virginia at the time of the American revolution and has been marketed as being an "authentic replication of the era" (Gable \& Handler, 2000,237). On the one hand, the managers of Colonial Williamsburg wanted visitors to form positive, lasting memories of their visit, whilst on their other, wanted to ensure that these memories were historically accurate and not fanciful Disneyland nostalgia (Gable \& Handler, 2000, 241). Despite this, people's memories when questioned years later, typically focused on family outings or were associated with souvenirs they purchased, the historical significance of the place was expressed almost as an afterthought (Gable \& Handler, 2000, 245).

This study suggests that the distinction between history and memory, one being objective and the other subjective, is not clear cut. Both are involved in constructing history. This most obvious example of this theory in action Gable and Handler note, is the difference 
between written and oral history. Attempting to translate written history without losing that objectivity, as Williamsburg has, ignores an essential part of what continues to make the pasta emotionally impactful and relevant part of people's lives (Gable \& Handler, 2000, 248).

Excavation simulations have long been a popular approach for getting visitors engaged with the process of archaeology. However, these are now widely considered to be unrealistic depictions with little actual value. Such sandbox activities are typically poor at replicating the actual conditions and purpose of excavations and create a misconception of archaeology as all about digging and treasure hunting (Thistle 2012, 68).As a result, many alternative approaches have been taken to emphasise the real value of excavation. Paul Thistle proposed one such approach where a square, flat sheet with model artefacts and features placed upon it was constructed to serve as a pre-excavated site layer. This emphasised the spatial importance of a site and focused on the documentation and mapping work required for in-situ material at each level of a site (Thistle 2012, 71). Presenting several different squares which served as different layers of the same site was used to help illustrate important interpretive concepts such as stratigraphy and relative dating. Ultimately, this approach was a successful way of directing the emphasis of excavation away from the artefacts and back onto the site itself (Thistle 2012, 74).

\section{Collection Practices for Museum Archaeology}

Museums have become more aware of the disconnect between visitors and archaeology in recent years and many have taken innovative approaches to remedy this. The South Australian Museum in Adelaide, for instance, came to the conclusion that although they held one of Australia's most extensive collections of archaeological material, it meant nothing if it was not being utilised (Walshe 2011, 39). The museum then developed an interactive research centre that aimed to get people (primarily university students and archaeologists) to realise the potential recent technological innovations could have for providing new information and context for artefacts that was not available at the time they were excavated (Walshe 2011, 41). The museum hoped that not only would this give their material a renewed purpose and justification for being kept, but that it would also serve as a way for the public to engage and appreciate archaeology in a more hands on manner (Walshe 2011,44).

However, the South Australian Museum relied on the fact that visitors were able to physically come in and engage with their collection, which in many cases is impractical. 
Realising this, the London Archaeological Museum took an increasingly popular approach to solving this dilemma. The museum constructed a series of boxes containing a range of artefacts which were sent out to various schools in the region. This proved highly beneficial as it meant that students could have access and interactions with archaeological content on their own terms and within the comfort of their own classroom (Hall and Swain 2000, 89).

This initiative not only maximised the accessibility and educational potential of the assemblages, but also helped lift the pressure off of the museum's storage facilities which had become a problematic issue in its own right (Hall and Swain 2000, 87). This of course is not a new approach and was attempted in New Zealand through the support of the Carnegie Corporation during the 1930s (McQueen, 1942). What this found however, was that this required a great deal of time and commitment for what ultimately produced mixed results. Generally, smaller and rural schools appreciated the material more as it was often the only exposure to museums they got, whilst larger schools with greater resources, tended to only use the cases as secondary visual aids (McQueen, 1942).

The critique of modern day collecting practices which generally focus on compiling a comprehensive representation of a culture or period as the ultimate goal has obvious relevance to museum archaeology. In his recent work, Nick Merriman has argued that such collection practices are unsustainable and that we must now consider what it is we are collecting and why. Museums need to have structures in place to avoid collecting based solely on personal preference, or even on academic value. He proposes that collecting must now focus on material that is most beneficial for presenting the subject and concepts to an audience (Merriman 2015, 257). A self-reflective approach, where collecting is seen as a form of interpretation, can help build stronger connections and greater insight into how collecting practices and cultural values have changed over time. Merriman describes such changes as helping to develop a "relational museum" (Merriman 2015, 255).

Merriman argues that a relational approach takes very specific topics that would normally only interest a small group of people and extrapolates them out to their widest possible extent to encourage interest from as large an audience as possible (Merriman 2015, 257). An exhibit on trees at the Manchester Museum, where Merriman is director, had the potential to incorporate botany, geology (fossilised tress) anthropology (impact of global warming and pollution), archaeology (impact on deforestation on settlement patterns) zoology (impact on species associated with trees/ forests) or even economists and brewers via 
the marketing and production of cider and vineyards. Furthermore, this can provides new opportunities to involve a range of community groups to help raise support and interest in the topic and for the museum in general (Merriman 2015, 260).

\section{Integration of Interactive Media}

Interactive media is undoubtedly an area that is becoming increasingly important in museums as technology becomes more accessible and capable of producing more authentic and immersive experiences. Catherine Clarke suggests one of the central problems for archaeological education, is in expressing the process of discovery and interpretation as a coherent narrative that is easily understandable to the general public. Archaeology is often considered the quintessential multi-disciplinary subject which, by its very nature, requires synthesizing to present information into one coherent narrative. This is of course something interactive media is particularly effective at (Clarke 2007, 276).

One of the most frequently cited examples of utilising such media is the Jorvik Viking and Archaeological Resource Centre in York. When developing the interpretive framework for the centre, a conscious decision was made to avoid tired clichés of museum presentation and develop a more immersive experience. What resulted was a time car tour where visitors followed a track around a range of reconstructed dioramas that intertwined material and information uncovered during the excavation. The tour was followed with a laboratory area where visitors could see the full analysis process taking place. This helped reinforce that archaeological interpretation is not simply about taking things from the ground and putting them in a museum case. This was done to recognise one of the primary goals of the centre: to clarify myths and misconceptions the public may have about archaeology (Jones 1999, 259).

Whilst the centre was successful upon opening, many visitors expressed interest in wanting to handle artefacts themselves. As a result, the archaeological resource centre was developed shortly after. This included a series of interactive activities and displays that complemented the experience of the main centre. These aimed to be both academically correct whilst still fun and engaging for the visitors. Technological innovations were frequently incorporated which utilised archaeological plans, maps and photographs to show how archaeologists interpret a site and the important spatial relationships that can be inferred from each layer (Jones 1999, 261). 
Whilst these good intentions may have produced an interesting and novel way of engaging the general public with archaeology at the time, the extent to which this actually presents an informed scientific depiction of the subject have been questioned in recent years. Criticism towards the centre and the time car tour section in particular, has drawn unfavourable comparisons to overly commercialised theme parks with little substance and that the centre has become increasingly geared towards young children. This criticism highlights an important consideration in the introduction of such material; that the value of such interactive experiences are only as good as the validity of their content.

\section{Indigenous Archaeology in New Zealand}

The value in emphasising the continued relevance of the past for local communities should be considered an essential aspect of interpretation for any museum. This is considered particularly important to indigenous groups and nowhere is this more notable than New Zealand. By encouraging the development of Maori exhibitions in collaboration with local iwi, Maori people have been given control over the representation of their heritage to an extent rarely seen elsewhere. However, this has often come with adverse side effects. Maori curators are constantly faced with the responsibility of being labelled experts in their field rather than as kaitiaki (guardians) for others. This is not always understood in a discipline that traditionally has been very paternalistic regarding the care and ownership of collections (Hakiwai 2005, 158).

The central focus for many taonga Maori galleries is to find ways to reclaim ownership of their cultural inheritance and connect it with a modern context. Ensuring the public are aware that Maori culture is ongoing and that the past and present are inseparable concepts, is paramount. This concept can easily be understood as part of the responsibility of guardianship and the curator's duty to share knowledge, both reconnecting taonga back to its whakapapa and through public consultation and education on respectful protocol and heritage management (Hakiwai 2005, 161).

The extent to which archaeologists and Maori interact in regards to archaeological site management has traditionally been considered poor, particularly in the extent to which the relationship is reciprocal in providing and sharing knowledge. The general concern is that as fieldwork is now largely dominated by contract archaeology, sites are selected by developers' rather than archaeologists. As a result, the work is no longer about research but about acting 
in response to an immediate threat and gathering as much information from a site before it is lost. This rapid nature of development work generally does not allow the same opportunity for public consultation or wider analytical assessment (Phillips 2010, 147).

A common criticism Maori typically have with archaeologists is that they tend to place the research potential of a site above its cultural needs. Although they appreciate that gaining such information is important, this should not come at the expense of the site (Allen 2010,162 ). As the nature of contract archaeology has shown, this is often out of the archaeologists hands and requires a closer arrangement between developers and local iwi when sites will be impacted. Fortunately, this is something that has been addressed in recent revisions to the Heritage New Zealand Act in 2014.

Despite such improvements, the responsibility of long term site protection is still an issue. Nigel Prickett argues that archaeologists are often too reliant on the provisions of heritage legislation and generally leave site protection to Heritage New Zealand or the Department of Conservation (Allen 2010, 164). However, it is absurd to think that these organisations can manage thousands of sites to the required level on their own. As a result, it is becoming increasingly necessary to reach out to the public to gain their support and assistance in taking responsibility for their local sites and making them aware of their conservation requirements (Allen 2010, 165).

Given that the Maori dimension impacts every level of heritage management, this kind of association would be particularly invaluable if instigated on a nationwide level. Direct involvement in the day to day site management can provide a stronger position from which Maori can address any concerns they may have with current operational practices (Rika Heke 2010, 208). Heritage landscapes are important in this regard as they are frequently utilised as a conceptual meeting point where European and Maori values can establish common understandings and expectations. However, it is still important to realise that Maori are not one homogenous, unified group and dialogue is often required at several levels within a community to establish strategies that recognise the unique considerations of the area (Allen $2010,175)$.

From this review of the literature it has become apparent that archaeological collections in museums have been closely tied to the academic practitioners who established them and are generally not developed for public interaction. This has meant that public education has often been neglected within museums and has resulted in a vague and distorted 
public perception about archaeology, largely based on dubious sources. Whilst public archaeology has become a popular area of discussion in the international literature in recent years, the New Zealand perspective remains speculative and lacks a uniformed approach. It is this gap in the literature which this thesis hopes to address. It is not expected that this will require a radical shift in museum practice, but rather provide a collaborative platform from which staff are able to utilise a wider range of external (and internal) resources and opportunities that are already available.

\section{Methodology}

As the literature on this topic in New Zealand is not overly substantial, this has largely been exploratory research. An overview of the central issues are presented from which it is intended future research can expand in new directions. Although the primary focus of the research methodology was interviews, a series of critical observations of exhibitions (primarily at Puke Ariki) provided insight into the content and approach museum have taken in utilising archaeological content. Additional educational and archaeological resources were examined to address some of the recent initiatives and opportunities developed around the country. As the information gathered concerns experiences and expectations relating to a specific subject, this research was qualitative in nature. This strategy was the most appropriate way of measuring these parameters as opposed to quantitative research which is primarily used in measuring statistical data (Elliot 2005, 153). However, it must be noted that the qualitative approach is not without its weaknesses. The main issue is that such research focuses on a specific area of enquiry in detail and does not provide the opportunity to consider the extent to which wider context factors play beyond a superficial level. (Elliot 2005, 157).Additionally, it is important to recognise that the majority of these interviews were conducted on a single day with no follow up. Therefore, these interviews only represent the person's opinions on the day they were questioned and cannot be taken as anything more.

This dissertation does not intend to resolve the problem of archaeological representation, but rather seeks to start a dialogue amongst the community regarding the possibilities of implementing an interdisciplinary framework. As the size and scale of the research was dictated by the conditions of a dissertation, the scope had to be limited accordingly. This restricted the opportunity to explore all of the institutions and avenues of enquiry in the depth originally intended. In retrospect, it was realised that since Puke Ariki's 
main exhibition galleries have remained much the same as when they opened in 2003, there was less visible evidence of Kelvin Day's influence (who only became director in 2013) than originally expected. As of 2015, the three main galleries are currently in the early planning stages of a major restructure. As a result, it is expected that Puke Ariki will provide a more valuable reflection of current museum archaeology practice once this has been completed. Additionally, it is important to acknowledge that Puke Ariki does not represent a regular museum. As a combined library, museum and archive it has a larger range of resources and level of funding at its disposal which gives it the ability to develop projects on a size and scale not afforded to most regional museums.

\section{Research Questions}

When the topic was first developed, the scope was narrowed down to answering two central questions:

1. To what extent is there potential benefit in educating the public about archaeology within the current scope of New Zealand museums?

2. Is there an adequate level of support and encouragement within the archaeological and museum communities to make this realistically achievable?

Secondary questions included; how is archaeological content currently being presented in museum exhibits? Is this providing engaging and interactive experiences for the visitor or are they simply there to inform? What are some of the preconceived ideas and expectations New Zealanders have when they see archaeological material in museum exhibits? How do these expectations match up with what they see and read in other sources?

In retrospect, the primary questions were still relevant to the research and remained largely intact. The main change was in expanding the scope of these questions from not only considering the potential of museum education to identifying and considering a much wider range of opportunities for archaeological engagement. The secondary questions, which were only ever intended to provide background perspective, quickly became redundant once it was decided not to examine public perception. Instead, the focus shifted to the perspective of museum staff and other archaeological practitioners. As a result, the interview questions 
changed quite dramatically over time, as the considerations and implications of the research direction became clearer.

\section{Interview Questions and Structure}

It was originally imagined that there would be a much larger emphasis in this research on exhibitions as they are still the primary way most museums convey their history and content to the public. It soon became clear that exhibitions that emphasised or explicitly referenced archaeological content were increasingly rare. As a result, the interview questions were adapted to focus on opportunities where archaeological knowledge was used to inform on the stories and concepts presented in the displays. Education was at one point also intended to be a much broader topic. As museum education staff typically have limited collaborations with other staff, this question was only asked of people directly involved in this area. Questions relating to the level of documentation and accessibility of the collections, opinions on interactive media in providing interpretation potential and the perspective of Maori relationships with archaeology were all incorporated at different stages as the potential answers and perspectives these type of questions could produce were considered.

The primary data was a series of one on one interviews between the researcher and selected interview subjects. It was decided early on that interviews were more appropriate than other approaches (such as a questionnaire) as direct contact with the subject allowed the opportunity to build up a personalised insight and a more adaptable line of questioning as the interview progressed. As a result, interviews were kept informal and loosely structured, with the questions acting as a thematic guide rather than rigidly defining the answers(Patton 1990, 289). By allowing the direction of the interview to remain largely in the hands of the interviewee, there was less chance of a misleading directional bias regarding what topics were brought up, either through the selected list of questioning or on the part of the interviewer (Elliot 2005, 157).

Although there was no specific order to the questions, it was decided to lead with a question about what the benefit of archaeology was. It was felt that this provided a good starting point for getting the interviewees thinking about the potential application of archaeology within a wider interdisciplinary context. As the interviews included two people from Heritage New Zealand, some of the questions had to be rephrased to make them 
applicable. As archaeological interpretation and public education are a central part of their job, this provided the opportunity to recycle some of the previously removed questions.

\section{Interviewees}

In total, 14 people were interviewed between the $8^{\text {th }}$ August and $21^{\text {st }}$ of October 2014. Puke Ariki was originally chosen to serve as a case study to examine how the appointment of its current director Kelvin Day, a trained archaeologist with extensive fieldwork experience within the Taranaki region, had influenced the perceived value and understanding of archaeology within the wider museum. The people interviewed at Puke Ariki included staff from the social history, photographic, taonga Maori, archives and education departments. Some of these interviews had been personally requested, whilst others were more opportunistic and organised while during the visit. The staff interviewed were Kelvin Day, Andrew Moffatt, Glen Skipper, Elspeth Hocking, Channelle Carrick, Gary Bastin and Keri Elvin.

The staff interviewed at Heritage New Zealand (Pam Bain and Amy Hobbs), were selected for the unique perspective they could provide on archaeological site management and how their approach to education programs differed from what was being done in museums. The five other interviewees were all people with archaeological training now employed in various capacities around the country, not necessarily involving archaeology. Peter Adds is a lecturer in Maori Studies at Victoria University and Michelle Horwood (currently a $\mathrm{PhD}$ candidate at Victoria University)was previously curator at Wanganui Regional Museum. Both were chosen for their accessibility and their unique experiences with archaeology they have had. Dougal Austin is a Maori collections curator at Te Papa, chosen both for his own perspective on archaeology, but also to gain an insight into the general perception of archaeology within Te Papa.

Janet Davidson was chosen as an interview subject due to her many years of archaeological experience both in New Zealand and the Pacific. This not only provided the perspective of a highly regarded member of the archaeological community, but also provided a historical perspective on the way in which the discipline has changed over the past 50 years. Louise Furey was chosen as her role at Auckland Museum is now the only position in a New Zealand museum dedicated specifically to archaeological curation. 


\section{Chapter Outlines}

The first chapter provides a brief history of the four major metropolitan museums in New Zealand, focusing on how their general stylistic and curatorial developments have influenced the way current museum practice has evolved and what role archaeology has played in this. Intertwined within this is a brief history of the founding years of the New Zealand Archaeological Association and how this heralded the beginning of the professional era for the discipline and a shift away from museums, towards the more academic and procedural focus within universities. The final section of the chapter examines Puke Ariki, outlining the history of the institution and a critical observation of its galleries. This provides context for many of the comments made in the following chapter.

Chapter two is comprised entirely of material collated from the interviews. The structure of these comments are arranged by themes which will be analysed in the third chapter. Specifically these are: the benefits of archaeology; the issue of documentation and interpretation for archaeological assemblages; approaches to archaeological education in museums; the potential value of interactive media; the relationship between museums and heritage sites and the strengthening of Maori relationships with archaeology.

The third chapter is a critical consideration and analysis of the concepts and opinions expressed in chapters one and two. For each theme, examples of projects in New Zealand which have utilised these ideas to develop engaging archaeological content are presented. A variety of both museum and heritage site based examples were chosen to re-emphasise the invaluable benefit these cultural avenues can have when working in unison for providing meaningful archaeological experiences. 


\section{Chapter 1}

\section{Background Context:}

\section{$\backslash$ The Changing Face of Museum Archaeology}

It is necessary at this point to provide a brief historical overview of museum archaeology in New Zealand to help illustrate the trajectory this has taken, primarily amongst the four major metropolitan museums. By showing the nature in which the discipline was entrenched within the museum provides an insight into how and why the transition into a professional discipline within universities removed the primary means of providing the public with a cohesive understanding of archaeology.

At the end of this chapter a section discussing the history of the Taranaki Museum leading up to the development of Puke Ariki is presented. This is followed by a critical observation of their current displays. This provides invaluable background context for many of the discussions by Puke Ariki staff in the following chapter.

\section{Archaeology in the Metropolitan Museums}

\section{Museum of New Zealand Te Papa Tongarewa}

In the early years of New Zealand museums, directors tended to have strong natural science backgrounds. Many of these men had long careers which helped define the unique identity of their institutions. James Hector at the Colonial Museum had a strong interest in geology and based his collection policy on developing his natural history specimens into a national resource. This meant however, that the museum's collections lagged behind the other three in its diversity and scope (Livingstone 1998, 4). It wasn't until his successor, Augustus Hamilton, was appointed in 1903 that ethnology and Maori culture was given any real attention. Hamilton's position was supported by the appointment of Elsdon Best as Maori ethnologist in 1910 (Simmons 1984, 2). Together, they utilised their own collections and personal connections to establish a sizable ethnological resource that promoted Maori life and 
craftsmanship (Livingstone 1998, 4). Best was recognised for promoting closer (for his time) relationships with Maori people. This was exemplified by his close relationship with Tuhoe which formed a cohesive link between his dual interests in Maori learning and European scholarship (McCarthy 2007, 69).

W.R.B. Oliver, Director from 1928 to 1947, was an early proponent of museum education and championed the idea of developing technical displays with a distinct educational value (McCarthy 2007, 77). Oliver had been inspired during his studies of overseas museum education which was funded as part of the Carnegie grant in 1937. However, he was ultimately unable to implement these plans following the outbreak of the Second World War. This greatly reduced the museum's staff, funding and access to the building itself (Dell, 2013b).

The enthusiasm of Oliver's successor, Robert Falla for fieldwork and various scientific pursuits resulted in a dramatic increase in scientific collections and re-established the museum's reputation as a publisher of quality scientific research (Dell, 2013a). Since this period scientific appointments have waxed and waned depending on the museum's strategic direction. There has never been an official archaeological position at the National Museum and archaeologists who have worked there in recent years, such as Janet Davidson, have generally held interdisciplinary positions(Davidson, pers comm. 2014).

\section{Otago Museum}

More than any other museum, the history of Otago has been defined by its relationship to the university. The University of Otago managed the museum from 1877 until 1955 when the Otago Museum Trust Board was established. This meant that during the early part of its history, the university had free reign over the museum and essentially treated it as an additional department. Director W. B. Benham for instance, was known to close the museum at lunchtime so that he and his students could work on the collections in peace (Harsant 1987, 9).

Benham's tenure as director did however result in the appointment of Henry Devenish (H.D.) Skinner as assistant curator and anthropologist in 1919. Skinner led a shift away from amateur traditionalists and placed greater focus on systematic collecting and the comparative analysis of material culture (Trotter 1997, 12). Skinner was simultaneously appointed as the 
first anthropologist at Otago University. Through this interconnected position and with his natural charm and power of persuasion, Skinner was able to bring in large and important collections that greatly enhanced the cultural diversity and prestige of the museum. Skinner was particularly enthusiastic in encouraging the public to participate in museum activities and support and fund projects through the establishment of the Friends of the Museum Association and his many public lecture tours (Harsant 1987, 9).

Although Skinner was known to lead day trips out to sites with his students and supervise excavations during the 1920s, he largely left the fieldwork to his associate, David Teviotdale. Teviotdale conducted fieldwork on Skinner's behalf, digging up an extensive range of sites across Otago and Southland (Harsant 1987, 11). As Skinner's focus was primarily on the taxonomic and comparative value of artefacts, little value was placed on their surrounding environment and these excavations are now regarded as haphazard and poorly documented (Trotter 1997, 14).

Despite this, H.D. Skinner was to have a monumental influence on future generations of museum practitioners and archaeologists. Many of his students would go on to their own influential careers in museum archaeology. However it was Les Lockerbie, a volunteer assistant, who Skinner appointed in 1947,(originally in an educational capacity), who would ultimately have the greatest influence on the discipline's future direction (Anderson, 2014). The systematic excavation methods he pioneered focused not only on the artefacts, but also their relational context and spatial environment and would come to define the modern approach to archaeological fieldwork (Trotter 1997, 14).Otago has continued to have a strong archaeological presence in the appointment of its anthropology curators. Stuart Park, Wendy Harsant, Dimitri Anson and most recently, Moria White, have all held this position, although their involvement with archaeology has been variable (Butts, pers comm. 2015).

\section{Canterbury Museum}

Julius von Haast's founding role at Canterbury Museum (1867-1887) was particularly instrumental for his time. Haast's pioneering fieldwork at moa hunting sites across Canterbury helped establish him as an early proponent of archaeological thought. This was most notably seen in his division of New Zealand prehistory into two separate eras defined by the presence and later absence of moa which, despite much alteration, remains the central 
principle in archaeological classifications today (Trotter 1997, 9). These discoveries allowed Haast to develop trade networks with museums around the world using the region's rich source of moa bones as his currency. From this, Haast accumulated a significant collection of international ethnographic material which would not have been possible to gain otherwise (Livingstone 1998, 21).

Roger Duff, first appointed ethnologist in 1938, was to become the next notable archaeologist at Canterbury. Appointed director in 1948, he had the advantage of being fluent in Maori, which he used to his advantage in building relationships and accumulating resources which added a unique cultural dimension to his academic findings (Simmons 1984, 3). Duff also utilised his educational background in the attention he gave to his publications. His clear writing style and ability to engage audiences with detailed illustrations was most notably seen in his landmark 1950 book The Moa Hunter Period of Maori Culture. These findings, largely taken from his excavations at Wairau Bar, provided a more sophisticated insight into moa hunting practices and helped refine his system of adze typology which remains in use today (Trotter 1997, 14). Duff's travels overseas encouraged him to incorporate international display approaches into his exhibits. His most notable innovation was the colonial street approach, which continues to be immensely popular and engaging with visitors, both at Canterbury and numerous heritage facilities around the country (Davidson, 2013).

Among the four major museums, Canterbury has had the most consistent level of active museum archaeologists in recent times, beginning with the first formal appointment of an archaeologist (Michael Trotter) in the mid 1960s. This position continued throughout recent decades until the departure of Chris Jacomb in 2002. Although no one was officially appointed to replace him, archaeology has continued to have a presence via the Senior Curator of Human History, Roger Fyfe who is currently responsible for the archaeology collections. Fyfe, who trained as an archaeologist at Otago, has had assistant curators involved in working on the registration of archaeological assemblages to maintain this important collection management responsibility (Butts pers comm., 2015). 


\section{Auckland War Memorial Museum}

Interestingly, the first long standing director at Auckland Museum, T.F Cheeseman, was a botanist with an interest in ethnology. This distinction had an immense impact in shaping the unique identity and traditions of the museum and helped set it apart from its contemporaries (Livingstone 1998, 22). Vic Fisher was appointed ethnologist in 1923 and shared Skinner's skill for encouraging the wider community to become interested and involved in the activities of the museum. Like Skinner, Fisher's focus was on categorizing artefacts as a mean of informing his academic theories. (Simmons 1984, 3).

Auckland museum's archaeological position is now the only remaining example of such traditional museum appointments. It survives largely as a result of the opportunistic circumstances in which it was established. The role of curator of archaeology was first established in 1965 as a result of Earl Vaile, a great benefactor to the museum who left money in his will to be used specifically for the purposes of obtaining Maori artefacts for the museum. This ensured that the position has continued throughout the years (Furey, pers comm.2014). The first appointee was Janet Davidson who, although still involved in developing the collections, considered the role to be as much about acting as an ambassador for archaeology to the public via open days, lectures and book publications (Davidson, pers comm.2014). She was succeeded in the mid 1980s by Nigel Prickett who focused on establishing a representative collection of international material. After he retired in 2008, Louise Furey was appointed in 2012 (Furey, pers comm. 2014).

\section{The New Zealand Archaeological Association (NZAA)}

The New Zealand Archaeological Association (NZAA)has its origins in 1954 with Jack Golson's arrival in New Zealand to take up the newly created position of lecturer in prehistory at Auckland University. Realising the need for some sort of unifying body, the association was gradually consolidated over the following years and was originally dominated by museum staff (Prickett 2004, 5). The early conferences (particularly in 1959 and 1960) focused on site excavations which were used as training exercises to bring the archaeological community as a whole, up to speed with the latest techniques and ethical practices (Prickett 2004, 13). 
By the early 1960s, a shift had begun to emerge in New Zealand archaeology which was clearly exemplified by developments within the association. In 1961 Jack Golson left for Australia and was succeeded as President by Les Lockerbie. However, Lockerbie was soon challenged and unseated by Roger Green from Auckland University. This challenge and its implications signalled a major shift in New Zealand Archaeology (Prickett 2004, 14). Although largely driven by Golson in Auckland, the association's heart had always been in the museums of the south and their charismatic leaders like Skinner and Duff. The support base that this old guard had acquired was largely amongst amateur volunteers. As the association developed, the influence of such groups declined and was replaced by a growing number of academic archaeologists who actively challenged many of the theories and positions previously deemed irrefutable (Prickett 2004, 14).

Although the influence of the academic faction within the NZAA subsided in later years, their position as the leading authority on New Zealand archaeology had been firmly established. Generations that followed were more receptive to new ideas and technology that could benefit the outcome of archaeology as a whole, rather than seeking institutional or personal prestige. Since this time, archaeology has become increasingly cross disciplinary as a way of establishing a greater knowledgebase and asserting its professional status in response to recent challenges and criticisms(Prickett 2004, 16). New ways of looking at the past have also contributed to the expansion outside of the confines of the museum as focus soon turned to wider site features such as pits, postholes and midden, with less emphasis on portable artefacts (Davidson 2004, 81). It is telling that the utilisation of aerial photography, ground penetrating radar and ancient DNA, all essential tools for modern archaeologists, were all pioneered by university archaeologists (Clayworth, 2014).

\section{Puke Ariki}

\section{History of the Taranaki Museum}

The original Taranaki Museum in New Plymouth has its origins in the formation of the Mechanic's Institute in 1847. By 1867, this was operating as a museum from the Provincial Council Chambers building (Hocking 2012, 27). By 1960, the Taranaki Museum and library had settled into the war memorial building. However, the museum was to be plagued with a 
lack of space which only grew worse as time went on. By the 1980s this was becoming critical, only $5 \%$ of the museum's collection was on display with the majority left stored in the basement (Puke Ariki, 2015).

However, it was not until 1993 that a working group was established to address the problem. By 1995 the site of the new museum was decided as the old Puke Ariki Pa. This site was chosen as it held mana for both local Maori and Pakeha. During the 1700s it had acted as a central $\mathrm{Pa}$ site for the area under chief Te Rangi Apitirua. Following a large migration of local Maori to the Kapiti coast, the site was then chosen as the settlement for the Plymouth Company in 1841. As the centre of the growing settlement, the hill was eventually removed to create more buildable land (Puke Ariki, 2015).

It was decided that this new institution should serve as a combined museum, library and information centre which opened on the $15^{\text {th }}$ June 2003. (Puke Ariki, 2015). It consists of three main galleries; the social history gallery (Taranaki Life), the Maori gallery (Te Takapou Whariki O Taranaki: the Sacred Woven Mat of Taranaki) and the natural history gallery (Taranaki Naturally). The content in these galleries today is much the same as when the museum opened. Additionally there is also a temporary gallery space which houses changing exhibitions.

Despite not always reflecting it in their exhibitions, the Taranaki Museum has always had a good reputation for being actively engaged in local archaeology and has employed several archaeologically trained staff over the years (Day, pers comm. 2014). Nigel Prickett was director for a period in the 1970s before taking up the position of archaeology curator at Auckland. Following this, Roger Fyfe spent several years at the museum as deputy director prior until moving to Canterbury in 1992.During his time at the museum, Prickett was involved in extensive site surveys of Taranaki pa sites (particularly redoubts) as part of his doctorate research and wrote a series of influential papers on the subject which continue to be utilised, most notably in the museum's Taranaki wars exhibition (Butts pers comm., 2015).

The museum is currently in the preliminary stages of a major redevelopment of these galleries. This will no doubt provide a more up to date physical reflection of the museum and its current direction. The current director, Kelvin Day, trained as an archaeologist and previously served as local file keeper and archaeological consultant for the Taranaki region. He has been with the museum since 1992 and was originally programmes co-coordinator and 
deputy director, followed by a period as exhibitions manger and heritage manger collections (Hocking 2012, 29).

\section{Critical Observations of Archaeological Content at Puke Ariki}

During the period in which interviews were conducted with member of the museum staff, time was also spent in each of Puke Ariki's galleries examining the extent to which archaeological content had been utilised, how this has been done and to consider some potential opportunities for future incorporation. The content in these displays had been utilised in a wide variety of ways, some more successful than others. In the social history gallery, a lot of the archaeological material had been recycled from material developed for the 2010 Taranaki Wars exhibition. Much of this related to the different types of defensive structures and their strategic and military importance. The two cases of material from the Omata stockade made it explicit that the material came from an archaeological site and provides sketch maps and photographs of the site as contextual aids. Together, this provided a clear sense of the type of defensive structures that were developed and how this has been established $(f i g ~ 1 \& 2)$.

The Maori Gallery approached the interpretation of archaeology from a range of different perspectives. In some areas, the circumstantial way in which many of the taonga had been discovered reflected archaeology's invaluable connections to conservation practices. This was highlighted in the nature of the work done on the epa panels and material from the landing site at Potakata which showed how Maori intentionally buried their canoe hulls in peaty water so they could return to work on them at a later date.

Two significant archaeological sites in the area, Te Rangatapu-Ohaure Tokotoko and Kaupokonui were given specific focus. The information provided, although not directly referencing archaeology, described how the range of animal bones recovered and their distribution alongside stone flaking areas led to their interpretation. Two images of the site were provided as interpretation; an aerial photograph indicating areas where moa bones were found and a drawing depicting how the site may have looked at the time of the adjacent village and moa butchering areas (fig 3). These panels were not particularly dynamic and required attentive reading by the visitor to clearly understand. Next to these panels was a case containing moa bones ontop a pile of stones (fig 4). Although it had no interpretation, it was 
intended to depict a moa hunter oven. This was originally part of an exhibit in the former Taranaki Museum which survived due to its popularity with audiences. Kelvin Day felt this invoked a sense of the past, not just for Maori cooking practices, but also for traditional museum displays and interpretation (Day, pers comm. 2014).

The series of adzes displayed in the adjoining section expanded upon this material and went into more detail relating to the production methods and sources used with evidence showing constant experimentation and refinement right up until European arrival (fig 5). The material in this area was interesting in two respects; the first was the way that provenance was handled. In several cases the origins of the taonga had been lost but rather than not displaying it, the museum deliberately acknowledged this. This showed the museum is not an all knowing entity and that there are always going to be gaps in their knowledgebase. This also provided an outlet for the public to provide any information or connections they may have. Secondly, the museum chose to present taonga in various conditions, not all of which are pristine, or even fully completed. Many show, and even highlight, the signs of wear and tear (fig 6 ). This was a subtle way in which the museum emphasised that these are not static items and have their own life histories and were once actively incorporated into people's everyday lives.

Another area featuring archaeological content was the pa architecture display. This examined the various uses of pa and some of their typical and atypical designs and materials. This area was enhanced by having an interactive touch screen which plotted pa sites in the area on a map. Visitors could then zoom in on locations to view specific sites and view related content. This content included survey maps, drawings, contemporary aerial photographs, historic photographs and in one instance; a reconstructed 3D model of a site presented as a video clip. This provided an invaluable level of spatial understanding for the variation and diversity amongst the sites ( $f i g$ 7).

The natural history gallery touched upon archaeological topics in several areas. The most obvious was the moa skeleton display $(f i g)$ ). This provided general information relating to the contrast in size and diversity between the different moa species which was informed by material from Richard Cassel's 1975 excavations. This provided a clear visual reference between how unarticulated bones appear in the ground and when they are properly arranged. Cassel's excavations were referenced again as part of a broader display depicting the local geological sequence where the rapid decline of bird species prior to human settlement, was 
illustrated by a list of native species identified from skeletal remains from archaeological sites of which the vast majority are now extinct. This emphasised that although moa may seem ancient, they are relatively recent developments

There were several other areas in the natural history gallery which could be enriched by the contribution of an archaeological perspective. The two most notable were the displays documenting the rich gardening culture in the region and the increasing environmental impact of coastal erosion. For the display on Taranaki's gardening culture, archaeologically retrieved information relating to prehistoric Maori gardening practices and unique adaptations could be incorporated. This could be particularly valuable as many of these features appear mundane when presented outside of a relatable context. Coastal erosion is having an ever increasing impact on archaeological sites resulting in the destruction of sites and the scattering of remaining material out of their contextual matrix. This makes recovery and interpretation increasingly problematic. Presenting such cultural considerations alongside the scientific could help broaden the public's consideration of the impact they are having and make them more aware of heritage management concerns. 


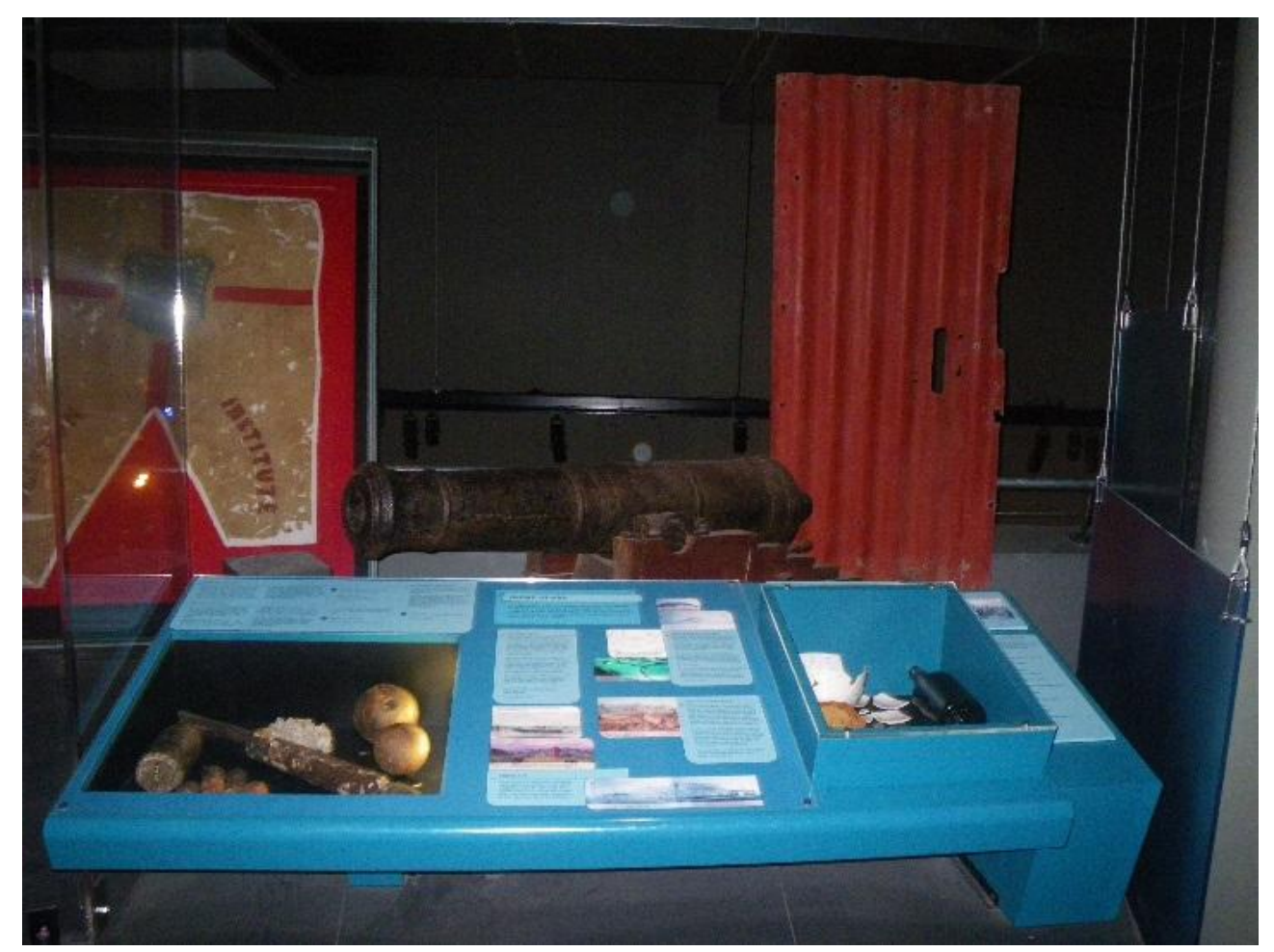

Figure 1 - Omata Stockade display based on material from Nigel Prickett's fieldwork. Social History Gallery: Puke Ariki (Photograph taken by the author, 2014)

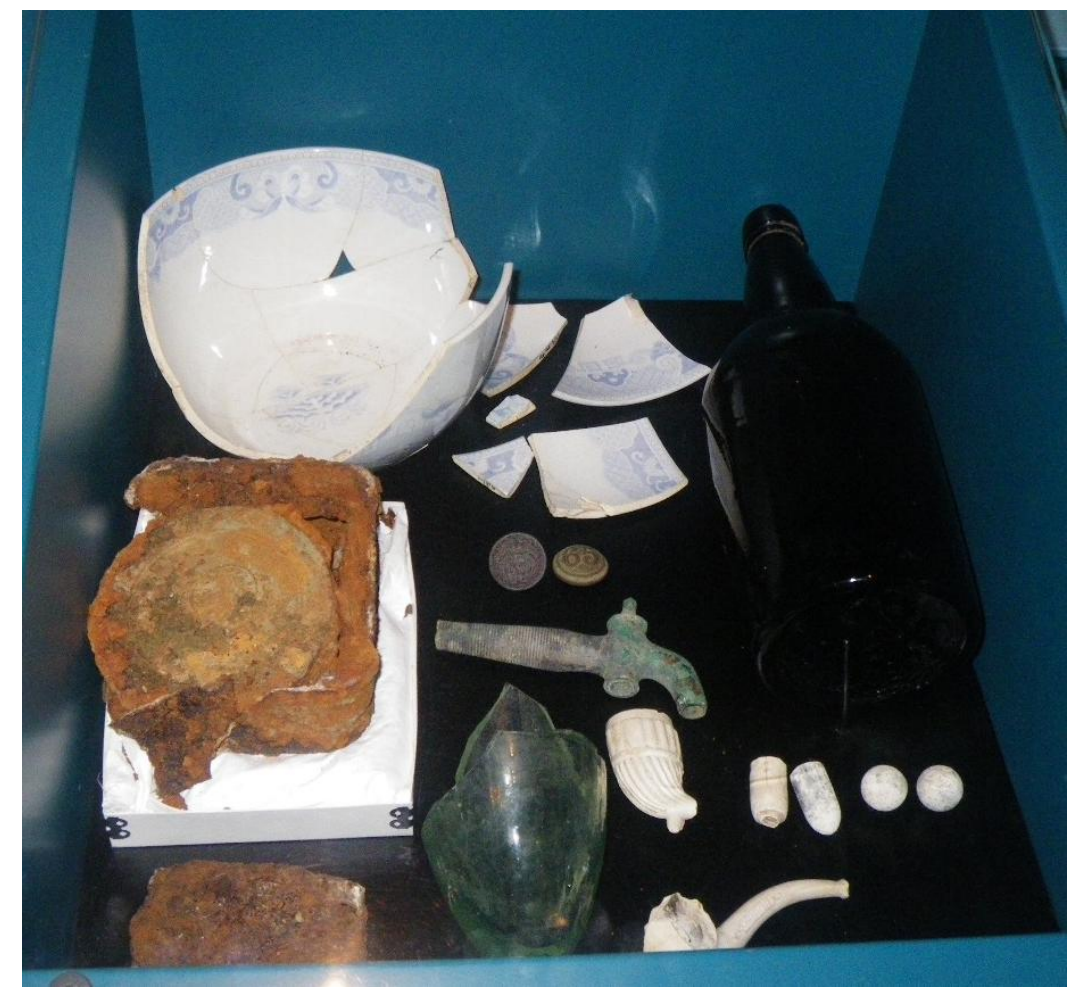

Figure 2 - Display case presenting a series of artefacts from the Omata Stockade Excavation. Social History Gallery: Puke Ariki. (Photograph taken by the author, 2014) 


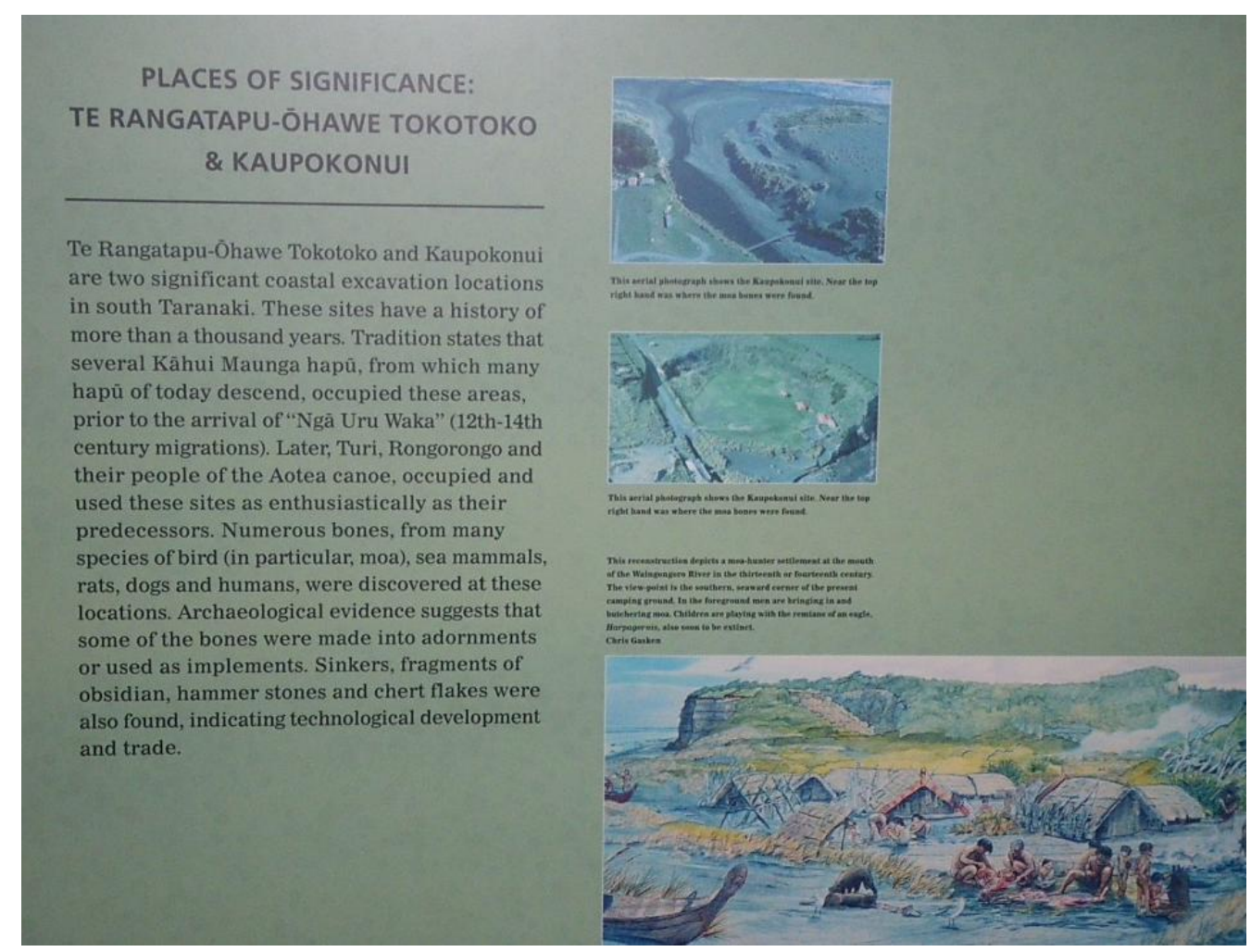

Figure 3- Places of Significance Panel including aerial photographs and illustrations of local archaeological sites. Maori Gallery: Puke Ariki (Photograph taken by the author, 2014)

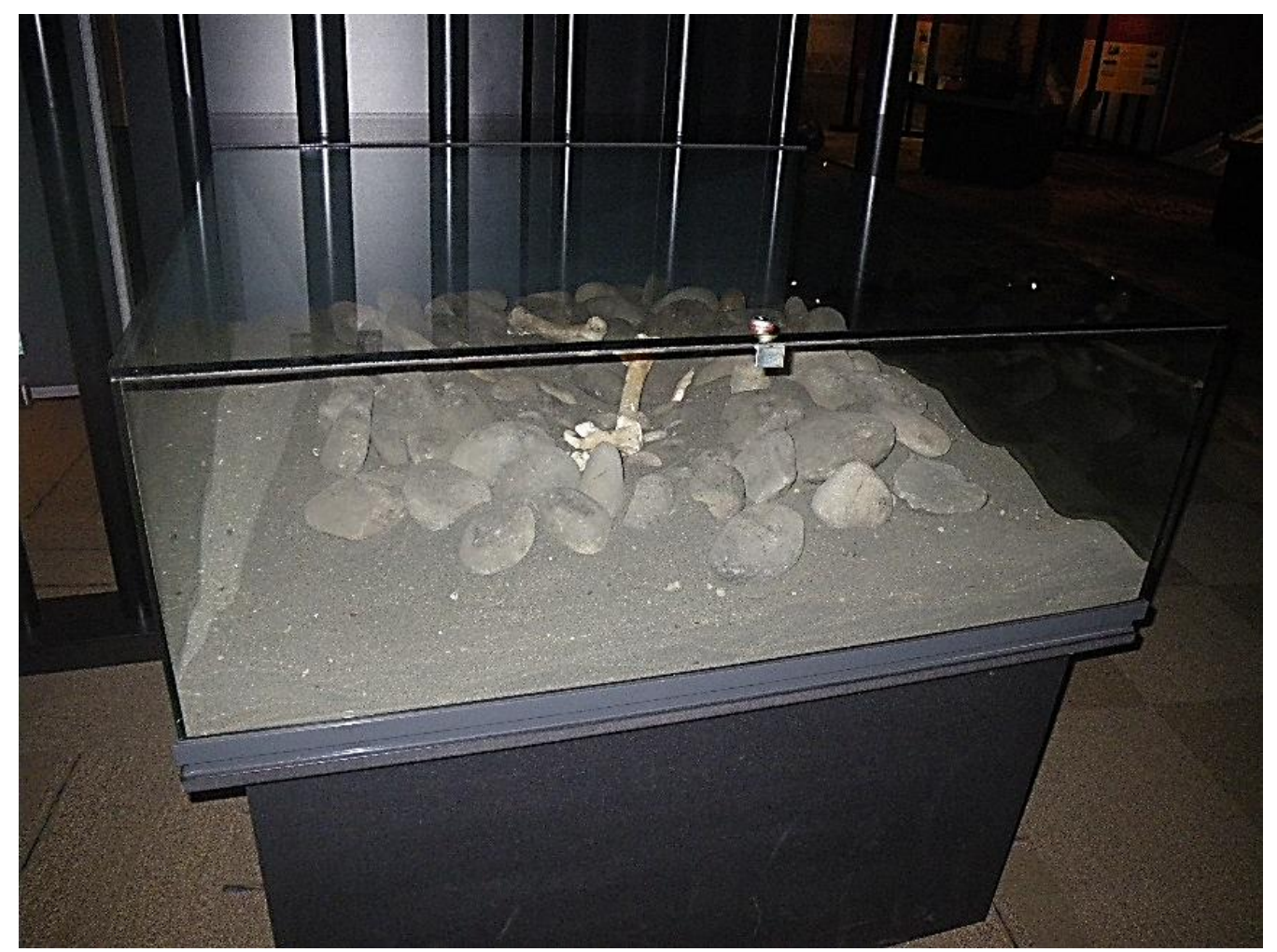

Figure 4 -Moa bones in oven display. Maori Gallery: Puke Ariki(Photograph taken by the author, 2014) 


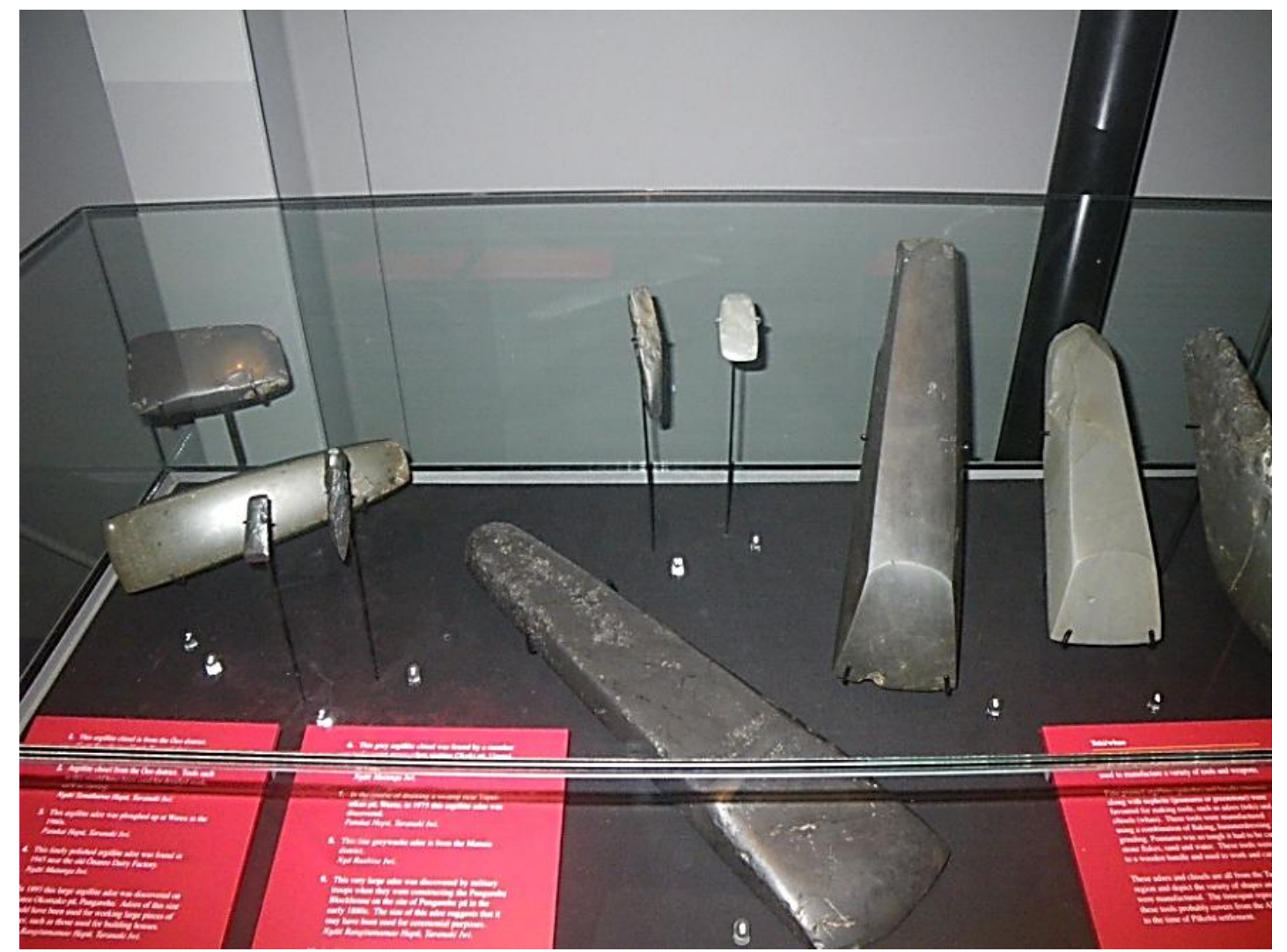

Figure 5-Adze (Toki) display. Maori Gallery: Puke Ariki (Photograph taken by the author, 2014)

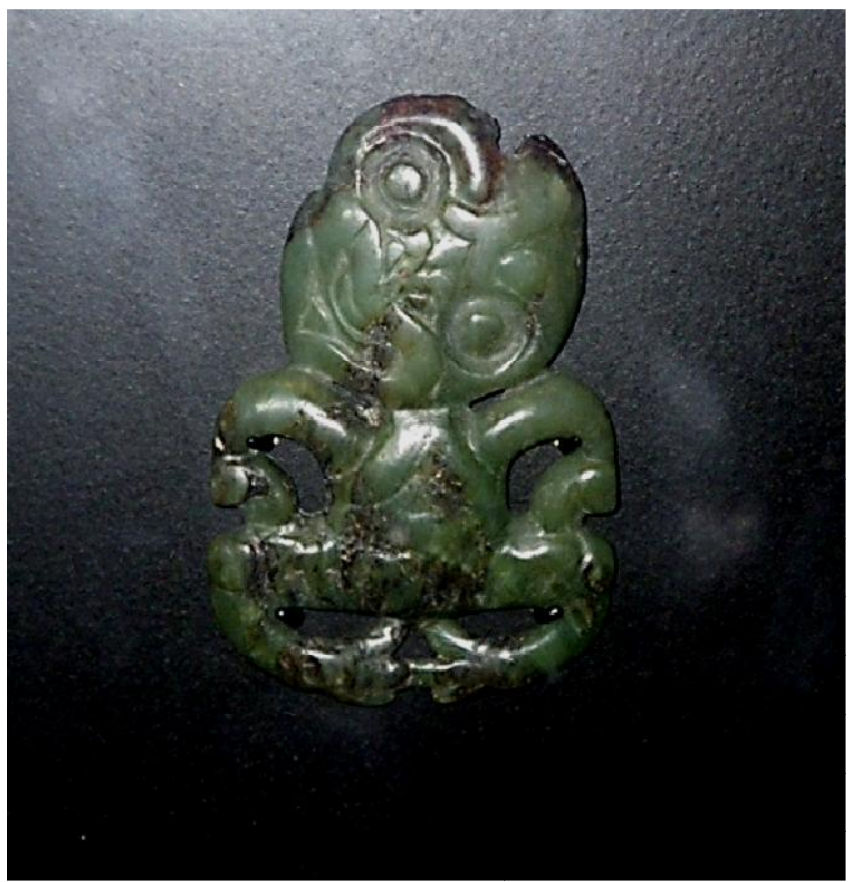

Figure 6 - Hei Tiki showing burn marks caused during heating process. Maori Gallery: Puke Ariki (Photograph taken by the author, 2014) 


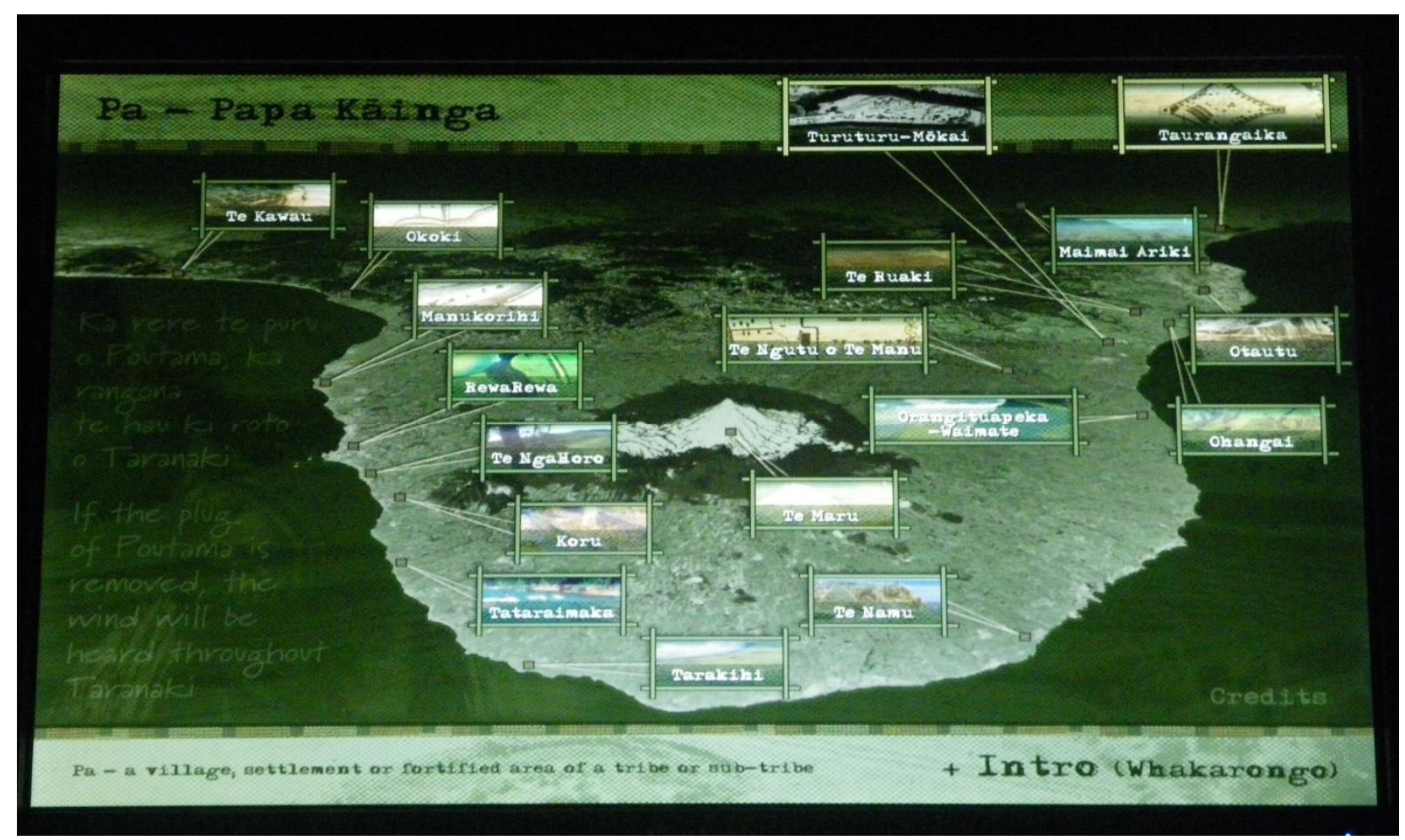

Figure 7 - Interactive touch screen display for local Pa Sites. Maori Gallery: Puke Ariki (Photograph taken by the author, 2014)

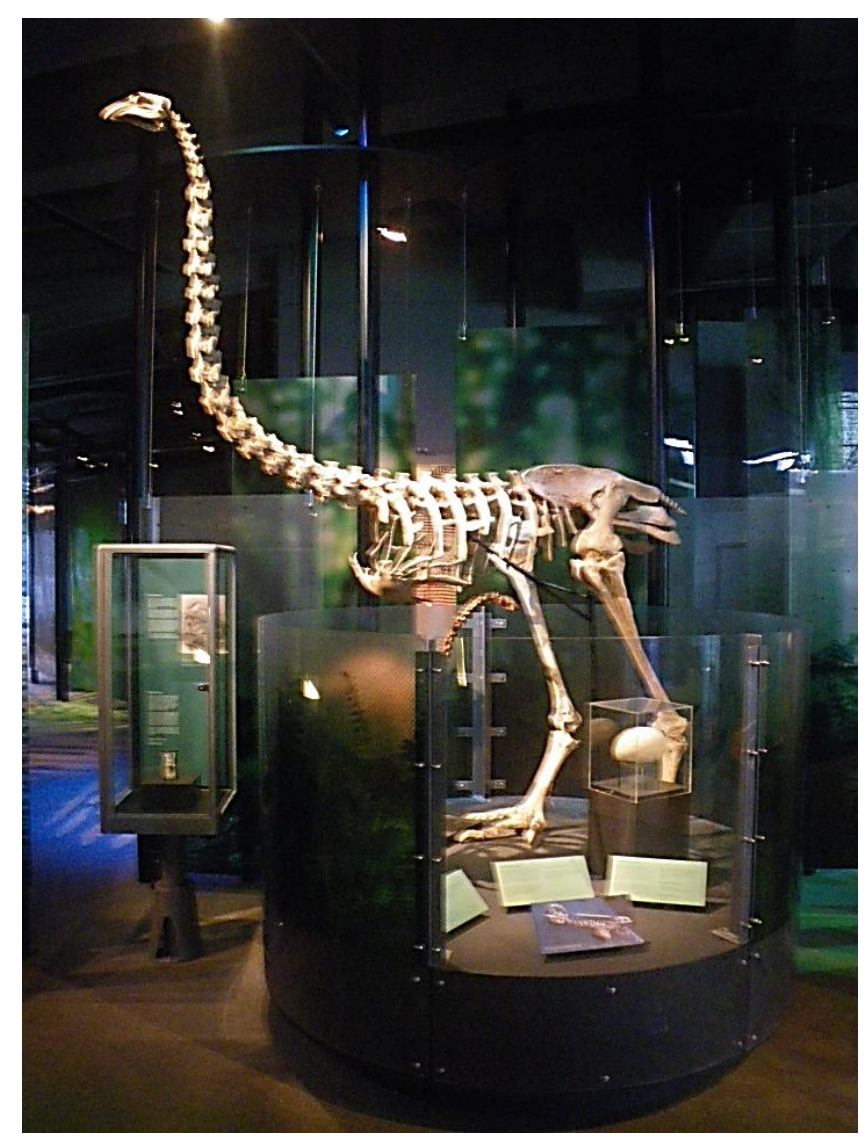

Figure 8 - Moa skeleton display based on material from Richard Cassel's fieldwork. Natural History Gallery: Puke Ariki (Photograph taken by the author, 2014 


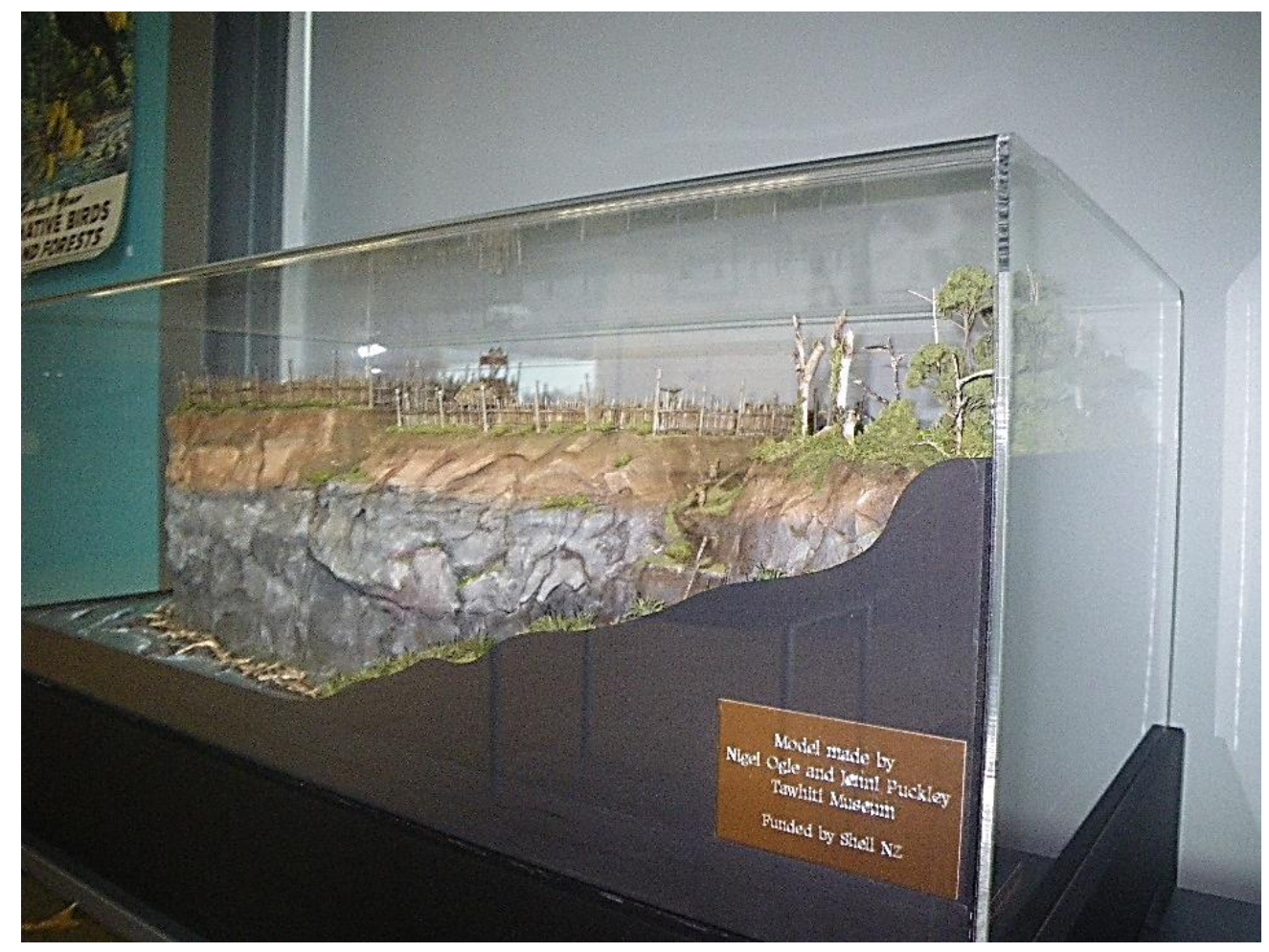

Figure 9- Model Pa. Education Department: Puke Ariki (Photograph taken by the author, 2014)

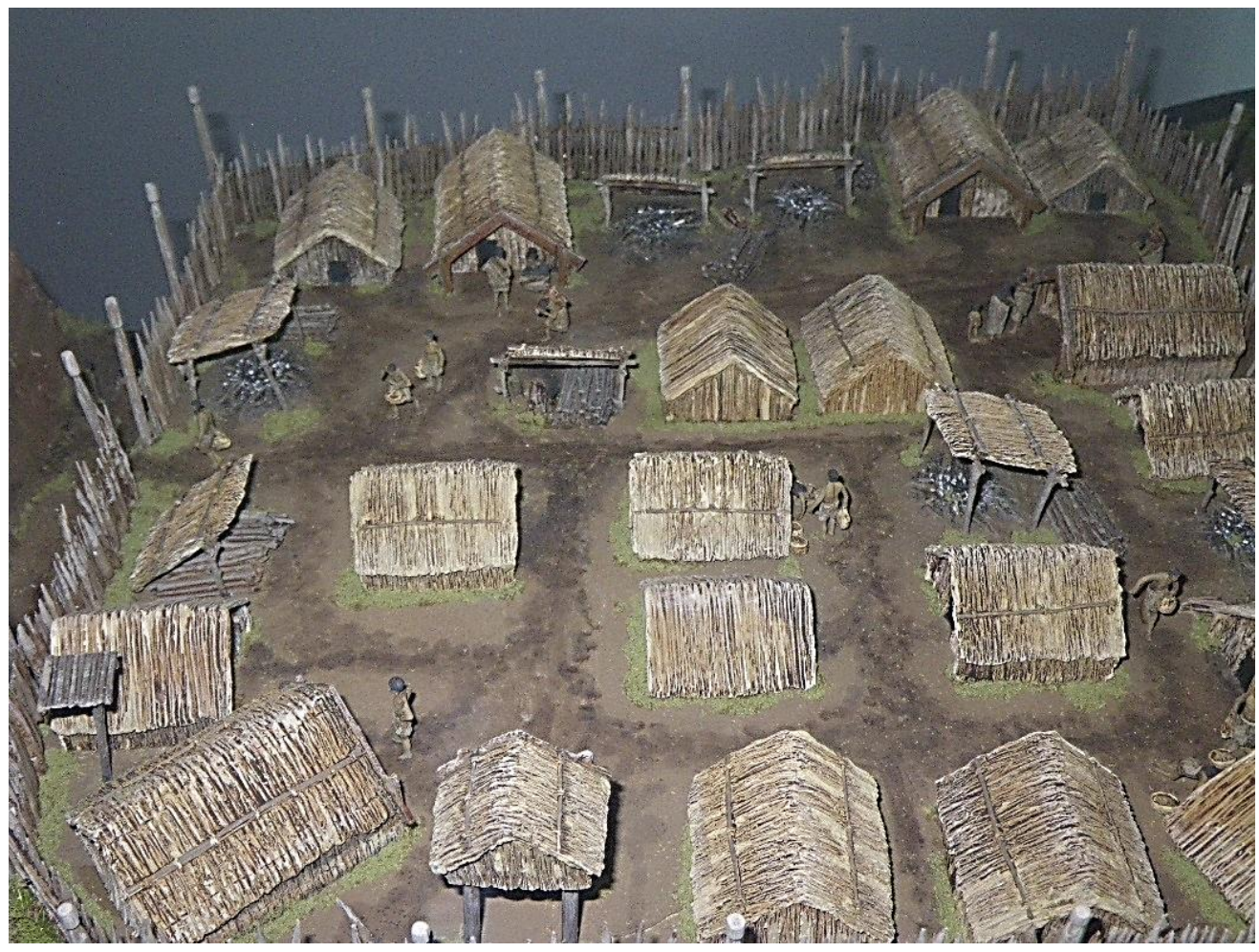

Figure 10-Detailed View of model Pa. Education Department: Puke Ariki (Photograph taken by the author, 2014) 


\section{Conclusion}

As this chapter has shown, the origins of archaeology in New Zealand museums largely grew out of the late $19^{\text {th }}$ and early $20^{\text {th }}$ century preoccupation with ethnology and anthropology. Early practice was divided between cultural theorists such as Best and the more taxonomic interpretation of material culture championed by Skinner. The third era acted as a merger of the two and signalled the beginning of the professional era. This not only considered the cultural implications and the potential that the artefacts could provide, but also added a third dimension; the site itself. This would prove to be a significant development, led not by the museum, but rather the growing university and independent archaeological organisations. The university's systematic, project led way of doing things put greater pressure on museum archaeologists who, as time went on, found themselves increasingly restricted in the extent that they could produce the same quality and quantity of academic output.

The critique of the exhibitions at Puke Ariki showed that although archaeology is still being utilised within displays, the phrase is not always explicitly used. Instead visual aids such as photographs, interactive panels and carefully arranged artefacts help to clarify the extent to which archaeological content has informed these interpretations. Puke Ariki, like most small regional museums, provides a much more general scope and does not have the same tradition of specialisation. Therefore, it is impressive that archaeology has been incorporated as much as it has. As the galleries are largely the same as when the museum opened in 2003, there is little direct influence of Kelvin Day's role as director. The more immediate impact can be seen in the understanding and perspectives of the current staff whose thoughts are presented in the following chapter. 


\section{Chapter 2}

\section{Interviews: $\boldsymbol{A}$ Hub for Future Exploration}

Although the observations at Puke Ariki were done as a secondary level of enquiry to support the findings from the interviews, they still provided an interesting insight into the extent that even a medium sized museum with a generalised scope can incorporate archaeological content. However, as the comments in this chapter show, there are a far wider range of opportunities for presenting archaeology than just what is shown in displays.

Despite the fact that the questions continued to evolve as my research progressed, the responses provided remained relevant to the six main themes. Together, the responses to these questions provided a clear sense of how the interviewees felt about the current level of archaeological representation in museums and identified a range of different ways that archaeology could be presented to the public. All comments in the following chapters have been taken from interviews conducted personally by the author unless otherwise stated.

\section{Benefits of Archaeology}

All of the interviewees agreed that archaeology has the potential to provide a wider context and sense of place for the stories and concepts presented within museums. The sheer diversity of content and its ability to provide insight across a long chronological sequence is what makes it such an invaluable resource. This can provide opportunities to discuss subjects such as how the material was identified, where it came from and the kind of information that can be extrapolated from this about the past in general. It was also felt that archaeological material has the ability to take an unfamiliar aspect of the past and make it relate to people on their terms. Whilst historical objects typically come from a single perspective, Puke Ariki director Kelvin Day notes, archaeological material (in the right context) has the ability to emphasise "the connections and relationships between people, cultures and their landscape all in one". 
Another benefit is the way that archaeology can illustrate different stages in the lifecycle of a museum object. Archaeological material is fortunate in this sense as it typically has a more dramatic process of site recovery and interpretation. Furthermore, the context and value attributed to an artefact is often emphasised differently depending on the environment it is presented in. Such narratives can also help illustrate an objects wider role in the interpretation process itself.

From his experience teaching Maori prehistory, Peter Adds believes that archaeology can be an invaluable educational resource. He notes that whilst most of the material that ends up in museums comes with some historical context, it rarely comes with scientific context. Archaeological material is therefore unique in that it comes with both and allows curators the opportunity to do a whole lot of analytical work that they cannot do with most collections.

Glen Skipper, Maori curator at Puke Ariki, believes that this potential is particularly important in many cases as museums representation are the only avenue that certain perspectives of Maori life can be found, which no longer exists in the landscape. This can be particularly valuable for areas such as Taranaki, given the circumstances under which the land and cultural connections have become dislocated from its people following generations of conflict.

\section{Documentation of Archaeological Material}

To further understand the role archaeology serves within museums, it was deemed necessary to understand the way in which the material enters the museum, what is selected (and why) and what influences how it is managed. All the people interviewed agreed that documentation standards today are far more comprehensive and robust than they once were. However, they also stressed that this does not make interpretation and incorporation within museum any easier. In fact, given the technical nature of archaeological material, it is often more difficult. Archaeological assemblages are unique in that their value is not as individual pieces, but rather as a series of items occurring within the same spatial context which represent a particular activity or site of occupation.

Many interviewees discussed the fact that museums today are far more particular about the kind of material they accept into their collections. Museums generally only accept archaeological assemblages from the local area with sufficient provenance. Assemblages are 
otherwise typically left in storage unutilised, waiting for the off chance that someone with the specific knowledge and interest will come along and undertake the required analysis. This point was reiterated by Andrew Moffatt, heritage manager at Puke Ariki, when discussing the colonial era Street family assemblage, who commented that "The Street material came with the understanding that we were very careful in selecting material from the dig..... taking the material that would work best in terms of interpretation in the long term".

This statement reinforces the idea that accepting such material today can no longer be a mechanical transaction and requires a collaborative human element in making judgments regarding the size and scope of material the museum is willing to accept and how this will impact the future value for the public as well as academics. Kelvin Day noted that such requirements, although sensible, often have a negative impact on the public profile of archaeology. As museums become more selective in order to utilise storage space, fewer collections are being offered to museums and are instead taken back to the universities and other institutional facilities. The greater issue however, is that even when museums do have material, it is not always able to be effectively utilized.

Former museum archaeologist Janet Davidson, feels this issue has been long standing. Opportunities to bring complete assemblages into museums are particularly challenging. While concern over storage space is understandable, this means that some of the most beneficial contextual information (which can only be gained from such comprehensive assemblages), is being lost. She feels that this is something that is not always understood in museums. Whilst she is all in favour of university research, she feels that specialised museum archaeology can still play an important and complimentary role. "You can't let the \{archaeological\} collections be managed by people who think that a collection manager can manage anything from snails to Rembrandt, which is what the modern tendency is," she commented, "You have to have an archaeologist who is a collection manager ... someone who understands what all the old collections are and why they're important".

Davidson believes that such overarching registration systems work well for the art objects they were primarily developed for, but are less adaptable to archaeology. Assemblages typically arrive as bags of bulk material which are impractical to separate out and provide a unique number for every fishbone and flake. This issue was considered by several interviewees as a reflection of the minimal attention archaeology has received within 
collection management policies and has a direct impact on their ability to be utilised and interpreted in the future.

\section{Utilisation and Interpretation}

As Davidson noted, archaeology is a specialist discipline that is very difficult for someone without the relevant background to recognise its potential uses. This is increasingly problematic for display purposes as there is not often the time or space to provide the necessary context to an audience. As a result, curators typically select items which have more of a visual impact and can speak for themselves. As Elspeth Hocking, curator of social history at Puke Ariki, explained; "it's a lot harder to make those stories sing in a display or research context then say, a beautiful Victorian gown or ceramics.... a lot of these collections have amazing historical significance but they don't have the impact that's going to draw people in. That's not to say they're not important and they won't ever go on display... they do tell a really particular, interesting story".

All the interviewees agreed that archaeological material requires more effort in finding ways to connect aspects into people's everyday lives. The most frequently emphasised interpretive solution was the ability to incorporate the material back into its cultural landscape. This was seen as important, not only for recognising the visible evidence of the past in the landscape, but also for gaining a sense of its cultural importance. Archaeological interpretation should not just be about the items, but about what information their location and arrangement can provide about people's daily lives. However, this focus is often at odds with museums who are increasing presenting themselves as a place of spectacle and awe. As Peter Adds notes;"A lot of what archaeologists are interested in tends to be associated with everyday life patterns of people.... the big culture history that people tend to be interested in isn't easily presented with a lot of this material...most archaeological collections are pretty boring ... occasionally you'll get a nice artefact that might be worth displaying, but that's pretty rare, especially in New Zealand".

This issue was also discussed by Channelle Carrick, photography curator at Puke Ariki. Rather than trying to make the museums work for archaeology, she feels they should be developing new ways for archaeology to work within the museum; "museums are moving towards using archaeological material to actually broaden their context in terms of actually saying this is how we got it, this is what it looks like when it comes out of the ground... 
we're not this magical institution that just has all this stuff, it came from people and scientific exploration in the field... I think there is an understanding that the best way to illustrate this is to utilise the actual material".

Most of the interviewees felt that developing a successful museum display directly about archaeology as a process is difficult, although not impossible. The main issue is that fundamentally, these are two very different things. Archaeological fieldwork is a multifaceted process with sporadic, ever changing interpretations from various contributors over an extended period of time. Museum displays meanwhile, are typically static and designed to present a concise overview. The opportunity to produce such specialist exhibitions are limited as curators are required to work within the larger parameters of the museum and its strategic direction. Generally it is only in smaller museums, where curators have more direct input, that opportunities to develop something like this can occur. The problem with this however, is that such museums generally don't have the specialist knowledge required. In most cases where archaeologists have been employed in museums, it has been in general curatorial positions which allow little opportunity for specialist deviations.

One of the most interesting comments raised during these discussions, was how the type of material that is most valued and looks appealing in museum displays; the clean and tidy finished products, are usually less interesting archeologically than the broken shards and midden. As Louise Furey, curator of archaeology at Auckland museum notes, providing this context is an invaluable opportunity for recognising archaeological input; "A lot of taonga in museums are the finished product and it's archaeologists and what we do that often informs on how these things were made. We see a lot more of the pieces and we think more about where that stone material was being obtained from, how it was being worked in a technological sense. I see that here and in other museums; that people know their taonga but they don't know anything of that background of what the stone materials are".

Several interviewees mentioned that whilst all museum displays are underpinned by one discipline or another, this doesn't necessarily mean that they have to be singled out and emphasised in their own right. Archaeology simply has a sense of intrigue in the public's mind that others subject do not. Dougal Austin, Maori curator at Te Papa, believes public interest of this nature should be encouraged as a starting point for greater discussions on the subject. This has the potential to help address the greater issue of how we relate to and understand the settlement and development of this country He also believes this is 
particularly important for keeping discussions grounded within the reality of the New Zealand context and to avoid becoming too sensationalist or overbearing.

It is also important to realise that traditional exhibits are no longer the only means by which museums can present archaeology. Content is increasingly finding its way into online collections as well as contributing to various aspects of education programmes. However, these have usually been small, opportunistic aspects and not intended to signpost archaeology or provide any sort of dedicated focus. Louise Furey felt it was particularly important for the public (and curators) to understand the primary value of archaeology as a multifaceted resource rather than a feature in of itself; "a lot of our collections are collected not for their display potential, but in order to curate them for the future .... we are a repository of material that's quite apart from a normal museum display function, we are here to provide storage and accessibility to very valuable information that can still contribute to ongoing research".

The essential thing that any archaeological presentation needs to remember is that it is the people and their lives that are central to what is being portrayed. Artefacts are certainly an important part of this, but they are not essential. The difficulty of these presentations lies in the fact that aside from historical images and reproductions, there are not a lot of ways the people themselves can be represented. This is becomingly an increasingly relevant issue now that the traditional solution museums once turned to, the display of human remains, are no longer seen as appropriate. One notable alternative is dioramas. However, developing effective ways in which to create immersive experiences through models can prove challenging. Ultimately, getting source communities involved in the interpretation and consultation is essential for providing a meaningful human element.

\section{The Relationship between Maori and Archaeology}

This question was not originally included but was added as the crucial role Maori engagement and involvement can haven promoting and strengthening archaeological knowledge was better understood. Although most of the material discussed is related to archaeological fieldwork and developing relationships outside the museum, this is relevant to developing long term reciprocal relationships that are important to establish long before arriving at the museum. 
Peter Adds believes Maori continue to have minimal exposure to archaeology. In most instances local iwi only find out about it when their local heritage is threatened and an attempt to try and minimise the impact occurs. Maori may end up understanding something about the processes involved, but otherwise they have little direct context for archaeology. In fact, many feel revolted with the whole concept given how it conflicts with fundamental Maori beliefs. Dougal Austin felt that such relationships vary between communities depending on the experiences they've had in the past. The primary measure of success, is how collaborative the archaeologist is when discussing the project and addressing their questions and concerns.

Austin notes that a lot of these feelings are a result of the negative colonial legacy still associated with archaeology which has not been properly addressed. He commented:

I think you have to look at the history of what's happened in museums, over the last 30 years, particularly since the Te Maori exhibition ..... going back prior to that, the archaeological viewpoint and the ethnological viewpoint held sway that was it really, there was no indigenous voice.... so where we're at today that's happened; more Maori working in museums, like myself, but there's still a bit of cautiousness about how you engage with archaeology because it was so domineering in that earlier time. To let it back in, you need to mediate it so the interpretive framework is not dominated by the archaeological viewpoint but still takes account of it.

This is an interesting point as archaeology's position within the museum has historically been at the forefront and has never really had to contend with such cultural considerations in this way. Given the controversial approaches archaeologists often took when interpreting Maori culture in the past, it is unsurprising that there are still many unresolved issues. Whilst it is important to recognise archaeology as an important museum resource, ensuring that its contribution is not seen as above or below anything else will ultimately be determined by the way in which it is defined within the framework of modern museum.

Due to the need to be scientifically objective, archaeologists have historically been poor at forging these relationships. Archaeologists often did not think to include Maori and would only do so once the real decisions had already been made. In his experience, Kelvin Day believes relations have definitely improved over time; Maori are now much more aware and involved with site activities and are actively encouraged to become involved in a greater 
level of enquiry and undergo training. He also believes that archaeological awareness and knowledge on their terms can provide Maori with a greater sense of agency and involvement in the interpretation of their past on multiple levels. As Pam Bain, senior archaeologist at Heritage New Zealand, explained; "We try to make it clear to people that sites are not just something that belonged to Maori years ago, but that the people living here still have an ongoing relationship.... telling some of the stories about some of the current people involved in helping us manage the place is also part of the interpretation which I feel is really important".

The ability to reconnect past communities with the present, can also be a way of helping local communities come to terms with their past and recognising the impact this continues to have in their lives. Glen Skipper notes that this tension, particularly in the Taranaki region, is often associated with deeper and more complex issues;

I don't think the general public realises that there is archaeology going on within our community, or even that there are things there that are archaeologically valuable... we don't really embrace our history as a community very well as there are some quite hard parts about it. To recognise that there is archaeology would recognise that there was somebody there before us and that they are important. The history, of this community anyways, is not very conducive to that. As a community we've had fights over water,... ecological fights, Waitangi Tribunal fights..... and land rights fights but (not in an archaeological way) the issue of lost heritage hasn't really been fought over.

\section{Relationship between Archaeological Sites and Museums}

Although these are two very different and often difficult concepts to compare and operate within different environments towards different goals, it was felt that this was still important to consider the various perspectives and considerations museums have on the subject. A frequent comment from interviewees was that although they provide very different experiences and perspectives, they are equally valuable for providing a comprehensive interpretation for archaeology.

Indeed, Michelle Horwood (formerly curator at Whanganui Regional Museum) felt that people gain a lot more from physically going out and visiting sites for themselves. Seeing 
the environment in which the events or places actually existed provides a more tangible connection and level of understanding. Quite often these experiences can embody a range of cultural values such as land preservation and indigenous identity which the visitor may not experience or consider otherwise. Carrick and Hocking shared similar thoughts. When they first started at Puke Ariki Kelvin Day took them on a tour around local archaeological sites in the area. They both commented on how these were not just the obvious pa sites, but also the more subtle signs of landscape change and reuse that informed museum interpretations.

Hocking believed that going out to sites with someone who can interpret these markers on the landscape provides a level of appreciation that is very difficult for someone without archaeological experience to get otherwise. They noted how Day tries to convey this to all the staff, even if they have no involvement with archaeological material. This was done to make them aware of the greater cultural context in which they operate and get them thinking across different areas of the museum when developing experiences and content for the public.

Peter Adds believes that museums are the best place to present archaeological material and stories as they have the ability to provide multiple levels of interpretation that sites alone cannot. The limitation of sites in his view are that they are usually only interpreted by one source, typically the Department of Conservation (DOC) or Heritage New Zealand. He felt that as active site management is limited, there is an ideal avenue in which local Maori could become involved. Providing personal stories about the sites and their wider context as part of this involvement, could also allow for a greater awareness of the concerns and practicalities of conservation and long term site management.

Pam Bain believes that the role of museums is ultimately to serve as a hub from which people can develop an interest in an event or place which encourages them to do further investigation and experience it for themselves. For her in-situ site interpretations help keep everything in context, not just the spatial orientation, but also the links to the people that created it. She feels that it is key to ensure that this is kept at the heart of the storytelling process. However, Bain noted that the interpretation of archaeological sites still needs to strike a careful balance between respecting the cultural value of the site by recognising the importance of protection, whilst still having something that elicits a sense of wonder and excitement for the visitor. 
Channelle Carrick believes there is no real reason why museums cannot take people out to sites to establish greater contextual and cultural interaction with the material. To her, this is a natural extension of the multifaceted relationship and involvement heritage site managers and archaeologists often have with museums; "I think museums have a responsibility to some degree to be a conduit for this kind of relationship; these are the kind of places people do come and say I want to learn about culture, I'll go to the museum. So if they come into the museum .... and they find out the museum is running a tour out to an archaeological site open day, this helps to continue the learning.... so I think museums are a halfway point between what's happening out there and what we put on display". This is a particularly interesting idea and suggests the ideal kind of relationship museums can provide within the contemporary realm of archaeology. The challenge however, is in finding interesting and immersive ways of bringing this all together.

\section{Potential of Interactive Media}

The rapid rise of technology into virtually every facet of our lives over the past 20 years has meant museums are often seen as old and out of touch if they don't incorporate some sort of interactive touch screen or reconstructed 3D model into their exhibits. Everyone interviewed agreed that the technology available to us today can provide amazing opportunities for enhancing the level of engagement and understanding the public can have with archaeology. Their feelings on the extent to which this should be implemented however, were more reserved.

Elspeth Hocking expressed particular concern with museums developing interactives simply for the sake of it and felt that the emphasis should remain on having physical objects out on display. She recognised that this is largely a personal preference and that whilst some people enjoy a high density of objects on display, others find it overwhelming and prefer the more direct presentation interactives and visual technology can provide; "Technology when done well and done in a cohesive way, adds depth and interest to exhibitions...if it's combined with objects it connects with different audiences. So for visitors who find it easier to engage with something visual or something that they can interact with then having that kind of opportunity can be really beneficial". 
Hocking did note however that recent developments such as collections online are invaluable resources in their ability to make more of the collection available to the public than would be physically possible to put on display. She feels that in this instance, it still serves the benefit of the collection as it is essentially an advertisement for the museum in providing the public with exposure to new content and encouraging them to come into the museum and see for themselves.

From an archives perspective, Gary Bastin notes that technology can become an invaluable conservation tool in the way it provides fragile material with a level of public access and visual interpretation that is not otherwise possible. This can also provide information about material in a more user friendly setting which provides a sense of time and depth that can bring the material to life in ways that books and photographs cannot.

Several interviewees felt that such technology will play an invaluable role and continue to provide new possibilities for the future of public archaeology. As the New Zealand public has limited exposure to archaeology which makes it a difficult subject to present without getting too technical, the integration of such media can be highly beneficial. The ability to relate to broader experiences is a particularly invaluable tool for translating archaeological concepts into traditional displays.

Archaeologists are naturally the best people to develop these interpretations as they know exactly what is relevant and are able to select material that would work best in a digital context. Furthermore, this provides a unique opportunity for the public to gain an insight into the thought process of the archaeologist as the site is interpreted in front of them, literally from the ground up. As Janet Davidson succinctly summarised;

Anything can be made easily interpretable for non-archaeologically informed people if you have the right interpreter... you have to have the ability to see parallels in things ...it's possible to interpret very complicated things in visually interesting and simple terms, but it's a real skill .... you need to find that hook that somebody's going to glance at and go wow. 


\section{Education}

Education was a topic that was originally intended to have a greater focus in this dissertation. This was later re-evaluated when it became apparent most museum staff are not directly involved with education programme which are largely operated independently from the rest of the museum. Furthermore, as museum education programmes are driven by what is in the school curriculum, the extent that specialist topics such as archaeology can directly be incorporated is thought to be limited.

Keri Elvin, education officer at Puke Ariki, explained that whilst there haven't been any direct focus on archaeology within their education programme, there has still been several opportunities where content has been incorporated. One such programme was developed to connect with younger children who were interested in birds. This involved talking about names of different Moa species, their environment and (for older children), utilising their skeletons to illustrate their biology and dietary processes. These activities were often developed to utilise content within existing museum displays such as the musical instruments in the Maori gallery were used to show how moa bones were often utilised as tools.

Elvin also discussed that although tailoring education programmes to specialist topics like archaeology is possible, it is not common as this requires a far greater commitment of time and resources from staff for what are often one off events. Such programmes are usually only developed when staff can recognise other opportunities where the material can be utilised. As a way of reconciling these limitations, Elvin runs workshops where material and concepts that have been developed but not utilised within their education programme, can be taken up by teachers and adapted within their own classrooms. During her time at Wanganui Regional Museum, Michelle Horwood recalled a holiday programme involving a mock excavation pit that was set up outside the museum for people to come and "excavate" artefacts. She felt this came across as very gimmicky with no real meaning to it. She believes that such activities need to contribute to a relevant subject if it is to hold any real value. 


\section{Conclusion}

The findings from these interviews incorporated a diverse range of perspectives from across the museum and heritage sector relating to the current (and past) role of archaeology in museums. A recurring theme was that archaeology is not something that needs to be presented in a direct and intrusive way, but is best utilised in ways that inform and improve upon the stories and content already on display. The advantage of archaeology as a multidisciplinary approach can therefore be seen to help connect the material with a diverse range of audiences who may not otherwise have any awareness of the value this can have in providing a clearer understanding of the past.

The considerations and perspectives provided by the staff at Puke Ariki, regardless of their position, were just as valuable to the research as the archaeologists. What was interesting, was the different values placed on archaeology's purpose within the museum. Archaeologists emphasised the value of archaeology as a contextual resource, whereas the general museum staff were more inclined to discuss approaches and opportunities for making archaeology more applicable and meaningful to a wider audience. As this research has already shown, there is certainly interest and potential for expanding archaeological experiences in this way. A range of potential directions will be discussed in the following chapter. 


\section{Chapter 3}

\section{Analysis and Discussion:}

\section{Taking the Museum into the Landscape}

The data collated from the interviews in the previous chapter were important for providing insight into the general attitude museum staff currently have in regards to archaeology's role in museums. This served as a sounding board for considering new ways of making archaeology more accessible and meaningful to a wider audience. It was quickly discovered that this would not be impeded by a lack of support, but rather, in finding an appropriate avenue in which to apply such opportunities within the tightly structured framework of the museum. This chapter examines some of the difficulties in utilising archaeological material in museums before then going on to discuss some of the potential directions that could be taken to resolve them.

\section{Documentation and Interpretation}

As the interviews have shown, the way in which archaeological material is perceived between museum staff with archaeological training and those without is quite striking. This highlighted some of the fundamental problems with reincorporating archaeology into museums. Archaeological assemblages are typically grouped in with either Maori or social history collections. Whilst this allows for a greater level of cross-disciplinary utilisation, this is only achievable if the curator understands the nature of the content they are dealing with and what can and cannot be done. Curators naturally look for ways to make direct connections with the assemblages that make them interesting and relatable to the public.

Recognising that archaeological assemblages are first and foremost a scientific resource, is key to understanding how they can effectively be utilised. In most cases, archaeological material serves as a storytelling tool, rather than as the subject of the story itself. Archaeological collections are most easily understood as a jigsaw puzzle; each piece by itself cannot tell us much, but when all put together, provide a much more powerful picture. 
Archaeologists working within museums, like Louise Furey, have the opportunity to work with a whole range of assemblages and can recognise the value of the material not as singular items, but as a broader comparative resource(Furey, pers comm. 2014). It is for these reasons many of the interviewees emphasised the need for archaeologically-trained collection managers to be employed within museums (or at least consulted on a regular basis).

Furthermore, archaeologists have the unique challenge of having to balance cultural perspectives and interpretation alongside the scientific in a relatively homogenous way. In regards to this, Peter Adds criticised the validity of Puke Ariki's current Maori gallery. For him, the gallery presents a historical narrative that contradicts what is understood from the archaeological record. He believed that this was the result of inadequate archaeological knowledge amongst the local iwi who developed the exhibition. As a result, they constructed what he perceived as an "'old history" out of sync with current understandings (Adds, pers comm. 2014).

One solution to this knowledge shortfall is to enhance the level of documentation and analysis provided when depositing material. This is often difficult, as assemblages and their ephemera are typically not kept together and have historically been dispersed across various institutions. Despite this, there have been attempts to improve such records in recent years. Louise Furey has gone back through many of the assemblages at Auckland Museum adding contextual data from site records into the collection database to enhance its research potential and produce a truly contextual archaeological assemblage (Furey, pers comm.2014).

Ultimately, the only way these issues can be resolved, is for museum curators and archaeologists to sit down and discuss their expectations when depositing and receiving material. Of particular importance is the level of interpretation and documentation museums expect the material to arrive with. The major difficulty would be in establishing an approach that works for people across all areas of the sector. Whilst archaeologists favour a comprehensive research resource, museums want to know that there are still ways to utilize it within displays and public programmes. There are no easier answers, but by simply having these types of conversations provides an insight into the other parties perspective and a starting point for building future relationships.

\section{Education}


The original hypothesis when starting this research, was that the public's understanding of archaeology would be enhanced by a greater emphasis on the process of archaeology within exhibitions. It was soon discovered, there are several practical and conceptual issues with doing this. Archaeological fieldwork(especially excavations) are most interesting when unfolding right in front of you. Museum exhibitions in general have historically featured static displays accompanied by a summary of larger, complex stories. This approach has naturally had difficulty conceptualising such ongoing developments as excavations.

Educational programmes, on the surface, appear to be similarly restrictive as they are required to have direct relevance to the school curriculum. Tailored programmes based around specialist topics such as archaeology, are only developed when content can be utilised for several different purposes. An archaeology programme could potentially be feasible if it took advantage of its multidisciplinary potential and presented the content in a way that informs on a wide range of both natural and social sciences topics.

This multidisciplinary approach is clearly emphasised at Explorama, a showcase day held once a year at Auckland Museum. Staff from across the natural science departments present material and activities designed to provide the public with a better understanding of what their discipline is really about. The archaeology section (developed by Louise Furey) has incorporated traditional activities such as midden sorting and assemblage interpretation as well as utilising visual aids such as videos to illustrate the different stages of fieldwork and the type of activities involved (time lapse videos are a particularly effective way of achieving this). Having other natural sciences on display alongside them, provides an opportunity to emphasise some of the diverse ways in which information gained from artefacts can contribute to the knowledgebase of other subjects such as zoology and geology. This helps the public to appreciate archaeology's role as an invaluable information resource rather than treasure hunting and dinosaurs (Furey, pers comm. 2014).

A more site based approach is the kid's dig programme Heritage New Zealand is currently developing at the Kerikeri mission house in Northland. Amy Hobbs (Heritage Destinations Manager) discussed how this is intended to incorporate a specially constructed pit in which school groups can come and uncover 'artefacts' from the site. Such activities have historically come under a lot of criticism for being very resource heavy with little real educational benefit. Hobbs emphasised that this is not to be a free for all digging exercise, but rather something that will allow students to gain some insight into the process of 
archaeological fieldwork within an appropriate context. Situating the site within a heritage precinct is intended to encourage students to think about how archaeology can help interpret the wider landscape via evidence of occupation trends and population growth in the area (Hobbs, pers comm. 2014).

As well as working closely with local archaeologists, the development team intend to incorporate content from other disciplines such as historians and engineers to provide the public with a richer visual resource. It is expected that most of what is being developed will target onsite and post visit education teaching. If successful, this initiative could potentially be expanded out across other areas of the country (Hobbs, pers comm. 2014). Although such projects are effective at getting school groups directly involved with the process of archaeology, their limitations must be acknowledged. They are still quite labour intensive and opportunistic and most education programmes do not have the resources to develop on this scale. Often a more subtle and efficient approach is required.

One of the more interesting examples of this are the model pa used at Puke Ariki (fig $9 \& 10)$. These are frequently utilised as dynamic visual aids to engage student's curiosity and encourage them to ask questions about it. This provides a starting point from which the education team can lead into a range of topics relating to site selection and construction and the various purposes and activities they can include. By not providing any interpretation and instead letting the children become drawn to specific details of the models, encourages a more self-guided and personalised interaction with the material (Elvin, pers comm. 2014).

Both of these examples are interesting in how they show New Zealand archaeology striving for a balance between providing engaging experiences and accurate information. This is a familiar approach that appeared in much of the international literature, particularly in the examples of colonial Williamsburg, the Massachusetts house museum and the Archaeological Resource Centre in York. Furthermore, such local initiatives have followed a similar model to the dual 'hands on, minds on' approach suggested by Kevin Bartoy. Whilst finding ways to develop student interest and curiosity within the museum or classroom setting are an essential starting point, a real world application is still required for getting them to consider the relevance to their own lives. As a result, such learning approaches ideally work best in conjunction with larger site based experiences. 


\section{Future Directions}

\section{Interactive Media}

The role of technology in supporting the interpretation of archaeology was perceived by most interviewees as an important and increasingly essential way of engaging with modern museum audiences. As important as historic photographs and sketches may be, they are ultimately static images and cannot provide the visitor with the same sense of spatial relationship between items and the landscape. For this reason, one of the most common ways in which this technology is being employed, is with 3-D interactive displays. These displays have the potential to bring various formats of diverse information together into one digital realm and present it as one interactive and visually engaging narrative. This can provides museum curators with the ability to provide a greater depth and applicability to their material and a tangible link to the artefacts that visitors can easily recognise.

Glen Skipper recalled two notable examples in the Taranaki region where interactive media was utilised to interpret local archaeological sites. The first of these was Te Oropuriri, a gunfighter pa at Bell Block. This involved a 3-D reconstruction that incorporated archaeological material uncovered from the site in 2002 and 2004 (Winder, 2005). This interactive panel was created using electronic survey equipment and was able to present visual evidence of different periods of hapu feuds and colonial conflict occurring in the area in the years immediately prior to the Taranaki Wars. As part of this 3-D reconstruction, a camera was used to take a fly over shot across the entire site to illustrate the different structures (represented as 3D models) and where they would have stood. Skipper mentioned how the visitor was also able to orientate the panel to examine specific features and areas of the site to see how it may have looked at the time (Skipper, pers comm. 2014). What was interesting about this site was that it was only uncovered by chance during the development of the local bypass road. It was only at this point that local iwi came forward with information about the site which archaeologists previously hadn't known existed. As the bypass was already in progress, the archaeologists only had a brief period in which to gather information before the site was covered over by the bypass (Winder, 2005). This reinforces the value of communication and collaboration of resources which, if realised earlier, could have potentially diverted the bypass and saved the site. 
The second interactive Skipper discussed was at the Omata Redoubt. This involved a curved screen which acted as a viewfinder that overlaid historic maps and images onto the physical landscape in front of them. Visitors were able to use the interactive to zoom into the trenches of the redoubt or focus in on the remains of a historic European homestead to see how it was structured and view the different artefacts (now in the museum collection) that had been used to inform this interpretation. The focus was ultimately on emphasising how the relationship between Europeans and Maori dramatically shifted over time. Skipper felt that presenting images and content from different areas of a site in this way was invaluable for clearly and succinctly demonstrating the different stages of a site's history and how archaeological material in-situ can enhance the value of the site as a whole (Skipper, pers comm. 2014).

The key to any 3-D interactive or reconstruction is that it must ensure that there is meaningful substance behind it which provides an avenue for learning that the physical object cannot. It is essential that the public is always aware that what they are seeing is an interpretation based on current theories and evidence and to only present what is there and not be tempted to provide fabricated material for the sake of completeness. This can have a negative impact and dramatically alter people's perception of the validity of the material and the justification behind it (Gomez-Robbles 2011, 43). Given the rapid rate at which interactive media is developing, restrictions are becoming less about what is technically achievable and more about what its objective is. The development of such resources requires a large financial and personal commitment and must be seen to provide a significant educational benefit to justify it (Gomez-Robbles 2011, 45).

Museums have always had difficulty in presenting archaeology as an ever-changing process. One way in which this has been addressed is through the use of blog sites. These are becoming increasingly popular, not only as platforms for engaging with the public, but also as ways for archaeologists to reflect on the work they are doing and share their thoughts on the process as it is still happening. One example is the blog written by the University of Auckland Anthropology department during their annual excavations on Great Mercury Island (Phillipps, 2015). By presenting information in an informal and more personalised way as this provides the general public with a more relatable introduction to the subject. As this project was a collaboration with Auckland Museum, there is also a section on their website discussing what is being done, the background history of the site and what this means in terms of archaeological potential (Auckland Museum, 2014). 


\section{Museum Relationships with the Cultural Landscape}

The key concept that was emphasised again and again during this research was that archaeology is not just about the objects that are dug up, but about its context in the wider landscape. The artefacts are the tools that help construct our understanding of human occupation; the landscape is the stage on which it happened. Therefore, it makes sense that the landscape should play a central role in this interpretation. What was interesting to note was how museums are constantly looking to provide their audience with authentic experiences that makes them feel like they are actually at the site. This is in spite of the fact that, in many cases, the cultural landscapes and locations still exist. Ultimately, museums are trying to bring the landscape into the museum, rather than bringing the museum into the landscape.

The cultural landscape has the potential to provide a more emotive and effective representation of archaeology then artefacts ever could. Encouraging visitors to physically stand in the actual location and get a sense for what it must have been like to live there can be an incredibly powerful experience for people and can help produce an emotional connection with the past. Such feelings were reinforced in the interviews with Carrick and Hocking regarding their experience visiting archaeological sites as part of their orientation to Puke Ariki.

There are of course many issues in developing site visits as part of the museum experience. The most obvious is physically getting people to often quite remote sites. Providing a greater incentive for them to go all that way should therefore be seen as an important objective of the museum programme. Selecting examples of local, urban archaeology may be alternative to overcome this accessibility challenge. This approach could further prove beneficial in challenging the public's perception of what they consider archaeology and allowing them to realise its broader scope. The issue with this approach however, is that urban landscapes are often drastically altered to the extent that they no longer represent the same context they would have at the time. Whilst interpretation can still be done, it is required to be more conceptual and rely on interpretive panels and additional resources (old photographs/ maps) which does not have the same impact as being able to see the physical evidence in person. 
Heritage New Zealand are one such place that is providing this type of interpretive experience. Unlike museums, they have the advantage of having the physical landscape at their dispersal. Part of their mission objective is to find ways to make these places more interesting and relatable to the public (Bain, pers comm. 2014). As a result, they are able to do a whole lot more in providing the visitor with authentic activities and experiences. Incorporating these activities alongside site visits allows visitors to appreciate the ways people lived in the past and can help bring historical practices back into local knowledge and in some cases, even reutilised in daily life (Bain, pers comm. 2014).

There are some obvious limitations to the kind of interpretation heritage sites can provide. Environmental conditions are a major issue for displaying artefacts in-situ as they are more likely to be exposed to ever changing environmental conditions than if they were kept inside an environmentally controlled museum. Therefore, such projects must weigh the safety of the objects against the opportunity to present an authentic experience. Such concerns reiterate the fact that heritage sites place less of a focus on collection management then in-situ interpretation and often have to work with local museums to establish the best course of action (Hobbs, pers comm. 2014).

One of the most unique and effective ways Heritage New Zealand has highlighted the value of archaeological landscapes, has been through the heritage driving tour they have developed focusing on the Waikato Wars. This resource serves as a secondary school teaching guide based around 11 sites located between Auckland and Pirongia. This material is compiled into a resource booklet which is extensive in the range of resources provided. A wide range of maps, both historic and contemporary, are designed to provide a reference for the students to orientate themselves when standing at the sites. Additionally, questions are asked of students at each stage which typically relate to why each site was chosen, what its strategic benefits may have been, how this changed as a result of the war and what this would have meant for the local people (Heritage New Zealand, 2014).

This resource has been developed in a way that allows the site visits to be easily incorporated as field trips into the school curriculum. It is expected this would mainly be utilised by schools within the central North Island as the travel distance would be minimal and the sites would hold a greater level of relevance. However, the content in the booklets is substantial enough that it could potentially be completed entirely within the classroom and still benefit the students. Additionally, the material has also modified to act as a form of self- 
guided tour. The material in the education resource is available as a downloadable app which includes audio tour material and a GPS map of the area. This can help enable visitors, to familiarise themselves, not just with the sites themselves, but also with the history of the surrounding area along the way. It is not expected that everyone is going to stop and see all the sites and many are more likely to use them as rest stops to break up a long journey.

This program has obvious parallels and potential benefits for continuing to educate people about the Taranaki Wars. Most of the content required to provide a driving tour of this area could no doubt be recycled from Puke Ariki's 2010 exhibition which produced a comprehensive range of relevant resources and visual content. The central location of Puke Ariki would also serve as an ideal starting and finishing point and would help connect the museum and the tour together as part of an extended experience.

\section{Maori Relationships with Archaeology}

The response to this question amongst the interviewees was mixed. Generally it was felt that whilst relationships have certainly come a long way in the past 30 years, they are not perfect. Neglecting to provide follow up information for iwi regarding the findings from local excavations was a particularly notable concern. However, this is often a reflection of the nature of the work that is occurring. Contract archaeology projects for instance, are expected to quickly move in and gather as much content from a site as they can before it is destroyed o otherwise changed irreversibly. Therefore, the nature of this work provides little opportunity to look back and reflect on intra-site relationships across the wider landscape. Field reports often take months or even years to produce and are then often kept within local archaeology repositories and doesn't provide the opportunities for shared understandings and cultural benefits iwi naturally expect. This can be particularly impactful as for many Maori communities this is the only experience they have with archaeology and leaves a long lasting impression.

A key part of relationship building is arriving at a stage where Maori feel comfortable utilising archaeology on their own terms. Janet Davidson felt it was important to encourage local iwi, to develop their own sense of agency within the process, from start to finish. In some cases, this requires getting their names on publications and allowing them to contribute 
to the academic side of the process and understand how this relates to what occurred in the field.

From personal experience, although there are certainly aspects of archaeology Maori are uncomfortable with, they are generally very receptive and interested in the kind of material and information that archaeology can provide. This is particularly apparent where issues of genealogy and broader cultural interactions are concerned. Providing them with the opportunity to become involved in the process as much as possible (and most importantly, allowing them to decide how they go about this) is the best outcome. Allowing them to become active participants in the recovery and interpretation of their own history helps to dispel the antiquated notion of archaeologists as grave robbers and encourages a renewed sense of ownership for their own history.

Getting local archaeologists and iwi running tours of archaeological sites together can not only help establish closer working relationships between the two groups, but also allows for an understanding that although there are fundamental differences between the two perspectives, they are not mutually exclusive and can exist in tandem. For archaeologists, this means being more sympathetic to cultural values when interpreting sites (e.g. where they walk, place signs). For local iwi, this gives them the opportunity to recognise the greater value of the site not just what it can provide for them on a local level, but across a much wider scientific platform. Such interactions often led to iwi becoming involved in the care and upkeep of otherwise unmanaged sites in their area. Encouraging best conservation and protection practices can provide a personal sense of pride and responsibility whilst ensuring the longevity and further utilisation of the site in the process.

A unique example of this reciprocal type of relationship is the Buried Village of Te Wairoa near Rotorua. The village was buried as a result of the $1886 \mathrm{Mt}$ Tarawera eruption and was excavated at various stages since the 1930s (Buried Village of Te Wairoa, 2015). The excavated sites are scattered across a twelve acre park, each with their own interpretive panels. The village is unique in the fact that it was occupied by both Maori and Europeans at the time of the eruption. As a result, the site contains European stone storehouses, hotels, cottages and flour mills intermingled with Maori whare and canoe landing sites. Visitors have the option of exploring the village by themselves, with a tour guide or, as a type of middle ground, be guided around by information on the village smartphone app. Each version 
provides various perspectives from both local European and Maori descendants (Buried Village of Te Wairoa, 2015).

A museum was established at the buried village site in 1999.As the visitor must go through the museum to get to the village sites. This was no doubt intentional and designed to provide a historical overview of the area before heading out and exploring the sites themselves. This emphasises the proximity to the Pink and White Terraces and the impact this had on local tourism and the close Maori and Pakeha working relationship that developed from it which continues to this day (Buried Village of Te Wairoa, 2015).This approach echoes the thoughts of Pam Bain and Channelle Carrick, who both viewed the museum's relationship with archaeological sites as essential for encouraging interest in the topic and acting as a conduit to a wider learning experience.

\section{Conclusion}

From the data analysed and discussed in this chapter it is clear that for archaeology to have any meaningful impact upon the public consciousness, it must integrate itself within a wider

cultural framework, both in and outside the confines of the museum. This requires providing the visitor with opportunities to understand the spatial and cultural values of archaeological material in-situ. As this chapter has proven, there are various ways in which this can be achieved. Interactive media, Maori collaboration and educational programmes are all interrelated opportunities which can provide such meaningful experiences. The Waikato wars driving tour is an excellent example of the kind of programme that can be developed when such resources are pooled together. However, it is not enough to simply inform the general public. Museum practitioners must also be made aware of such opportunities and archaeology's power as a multi-disciplinary tool that can contribute to all facets of the museum experience. 


\section{Conclusion: Working Towards Multiple Horizons}

This dissertation set out to explore the perceived role and potential of museum archaeology in New Zealand. Archaeology is a subject which on the one hand, has always had a strong public fascination but on the other, a poor understanding. The role of the museum as the primary source of public knowledge about the past has been challenged in recent years as television and online resources continue to have a powerful impact on the public consciousness. This was originally attributed to the belief that museums were not providing enough opportunities to educate the public about archaeology through their exhibitions. However it was soon discovered that the issue was much more complex and multifaceted than it originally seemed.

Museums are now far less specialised then they once were. Collection managers are required to work across multiple departments and manage a broader range of content. This means that unless they have had experience with archaeology elsewhere, it is difficult for curators to recognise the value of the assemblages, never mind knowing how best to utilise them. Archaeology had a more defined role in the museum in the past when they served as research institutes where staff gathered material to advance their scientific endeavours. This role was subsequently filled by university anthropology departments, this left museum archaeologists without a discernible purpose.

A lot of this is a reflection of the way in which the profession has developed. Prior to the 1950s, archaeology in New Zealand had a strong amateur presence largely associated with charismatic museum directors such as Roger Duff and H.D. Skinner. However, following the development of a refined fieldwork methodology and the establishment of professional and ethical standards, amateurs were effectively shut out. As Merriman has noted, removing such opportunities to engage with archaeology only results in the public constructing misinformed perceptions from dubious sources. The shift from museum to universities also took away many of the opportunities for public engagement as the debates and new developments remained largely within academic circles. Although this has changed in recent years, a noticeable knowledge gap was allowed to grow. This gap developed not only between the public and archaeologists, but also between archaeologists and the museums they had once facilitated. 
For the most part, management of archaeological content in museums is mixed. Aside from the position held by Louise Furey, there are no remaining museum roles dedicated to archaeological curation in New Zealand. Whilst some interviewees felt strongly that such positions are required to understand the unique and invaluable context of archaeological material, the same could be said for virtually any scientific discipline that face similar restrictions in their ability to provide appropriate museum representation. Therefore this should not be seen as a problem exclusive to archaeology, but rather a reflection of the lack of specialist roles within museums in general.

Due to the disparity that has developed between the public and archaeology, museum archaeology can still offer a valuable service to academic institutions. Museums provide a unique avenue from which the information generated within the archaeological community can be processed and interpreted specifically for public understanding. In utilising the support and resources from across a wide range of disciplines, museums are able to provide introspective content that is more accessible and relevant to a general audience. This is something archaeologists today are not always aware of. I therefore argue that a partnership should be established between the two parties to establish a mutual understanding. However, as this research has shown, this would need to address several major considerations.

The value of archaeological material for museums and the value for archaeologists is quite different. While archaeologists favour retaining complete assemblages as a resource for future research, museums value specific interpretive and educational perspectives that can produce meaningful connections with the public. This is ultimately the crux of the problem with museum archaeology: who is it for, the public or the archaeologist?

Archaeologists for a long time regarded museums as a storage facility where they could deposit material and expect it to still be available years later. For such assemblages to remain in museums today, their value as multifaceted resource must be recognised. Instead of depositing raw data, archaeologists must work in collaboration with museums to discuss what is required to make the assemblages usable within the wider museum programme. Museums are now more selective in the material they accept and generally prefer that assemblages are broken into smaller, manageable sections. Ensuring that the documentation is comprehensive enough that the artefacts can still be returned to their original assemblage if required, is essential for providing a long term resource that is valuable for everyone. 
Education programmes within museums are often seen as an appendage rather than a vital organ. In most large museums education programs, already restricted by the requirements of the curriculum, are left to the education officer to develop with minimal input from the curators. In cases such as archaeology, the programme developer has little awareness of what material is in the collection and more importantly, what can be utilised for telling certain stories. The development of education programmes need to be recognised as a two way dialogue that encourages curators to contribute and perceive the value of their objects not only as collection items, but also as educational resources.

The concept of museums as an educational springboard is an important consideration in this regard. This can provides visitors with the opportunity to go out, investigate and experience the culture and the sites for themselves. Understanding that just because education programmes are developed within the walls of the museum, does not mean that they should be restricted to them. This can open up a whole new range of opportunities for audience engagement. All areas of the museum, whether utilising collection items, interactive media or written text, should be structured with this type of relationship in mind.

Archaeology as a publically-funded discipline, has a responsibility to give back to the community that supports it. Public lectures and site visits should be seen as more than just a goodwill effort, but as a natural part of the job. Getting local communities involved and contributing to the activities and discussions about archaeology, both in and out of the museum, is essential for creating a positive and informed experience that the public can draw upon in the future. By taking people out to sites and providing them with appropriate context to understand what they are seeing, allows them to come to their own conclusions, encourages a greater sense of ownership and agency and ultimately, become active interpreters of the past.

This sense of ownership with the past is already a central focus of taonga Maori galleries. Particular attention is given to emphasising the ways in which whakapapa is integrated into modern society and recognised as a living past. This approach should be taken a step further and applied to European perceptions of the past. Providing a frame of reference in which aspects of the past are made relatable to the visitor and evoke personal experiences and knowledge is essential to achieving greater awareness and public support for archaeology. 
Aside from the implications this thesis has for current museum practice, it also holds valuable academic significance. The research has been of an exploratory nature and has investigated an area of museum studies that has seen little academic attention in this country. It has made a contribution to the wider disciplines of museum and heritage studies by providing a fresh perspective on the way specialist disciplines can still serve a purpose within the current framework of New Zealand museums. This is something that all scientific disciplines are struggling with. By demonstrating how incorporating different community and disciplinary perspectives can provide a more relatable and immersive experience for a much larger proportion of the general public, is something everyone can learn from.

Archaeology is the quintessential multi-disciplinary discipline which, as this dissertation has shown, provides a wide range of opportunities to connect with different audiences. As Bruce McFagen states; "No artefact has a single intrinsic meaning, it not only has a context, it is part of a context, indeed many contexts. It can 'speak' to a viewer on different levels depending on whether or not the viewer 'recognises' it" (McFagen 1984, 6). Archaeology should therefore not be seen as one single concept with one defined definition, but as something that holds unique meaning for each individual. The challenge is now in finding ways that will allow these connections to be expressed. Such an approach would not only consider the wide range of learning approaches and relationships visitors may have with archaeology, but more importantly, provide opportunities for different communities to come together to share their perspective and interpretations.

As this research developed it became more than just a question of understanding archaeology's role in the museum, but about the larger operational framework in which it operates. Public archaeology in New Zealand needs to take into consideration all of the different facets and perspectives that are available to provide a comprehensive and multifaceted experience that establishes what archaeology is about and what it hopes to achieve. It seems that all of the heritage and community avenues required to produce such a framework are already in place, all that is required is a central core to tie them all around. I would argue that this core is the museum. Encouraging members of the wider community to act as archaeological interpreters in their own right, can help channel the information and values expressed by the institutions into a more direct and relatable context for the general public. This ultimately emphasises archaeology's value as an all-encompassing discipline that holds meaning on multiple levels and cultural benefit for all. 


\section{Appendices}

\section{Appendix I: Interview Questions}

1. What is your professional background and what kind of knowledge and experience have you had with archaeology?

A) What are some notable projects you have been involved with that incorporating content relating to archaeological practice and interpretation?

How well do you feel these were done and were there any restrictions and/or difficulties faced in achieving this?

2. Based upon your experience, what do you see as some of the potential benefits of utilising archaeological content within museums that you cannot gain elsewhere?

Do you find these type of benefits are typically recognised by most museum staff? Within the collection policies?

3. Do you believe that in situations in which archaeological content can potentially be utilised in supporting or broadening the scope and context of an exhibit or narrative that this is being recognised and integrated?
A) Are there any restrictions that you feel limit the extent to which this can be accomplished?

4. How do you find the documentation of archaeological content within museum collections to be in regards to its ability to provide a broader contextual relationship and interpretation?

I.e., for recognising an artefacts' association with other connected archaeological content (e.g. excavation photos, maps, site reports etc).
A) Do you feel such relationships are easily interpretable for non archaeologically informed people?

5. To what extent do you feel that the interpretation of archaeological content can be enhanced through the use of digital technology as far as providing a greater visual \& spatial dimension to the material and the development of narratives is concerned? (e.g. interactive maps/ 3 D site reconstructions)

6. Given its historically strained relationship, how do you feel archaeological practice is perceived amongst the Maori community in general today? 
Are they well informed about its value and potential for establishing stronger understandings/ relationships within the community?

Are they involved to a sufficient level in the interpretation process?

7. Finally, do you believe that the current extent of archaeological representation within museums is appropriate or do you feel such content is better served via other cultural avenues such as heritage site visits/ tours, site open days etc?

\section{Appendix II: Particular Aspects of Museum/ Heritage Site Displays}

(NB: these were questions I considered whilst looking around exhibits and did not directly inform the results of my analysis)

How varied are the media the exhibit used to present the archaeological concepts (artefacts/ photographs/ video clips/ diagrams / quotes) are they stand alone features with their own context or are they integrated?

How much space is provided for the exhibit in the gallery? Is it a central feature or overshadowed by others (i.e., developed as an afterthought)?

How well is the material spaced in the display? Is it cluttered together to fit as much in? Is there enough room to clearly present itself and its significance?

To what extent does lighting and colour impact the display? Does it try and present a certain type of mood? Emphasise any particular artefacts and features?

How much text is used? Is this used effectively? Does this provide a basic succinct understanding of what archaeology is/ how it is applied and how it can be perceived and recognised in a New Zealand context?

How does the level of text reflect the perception of archaeology by the exhibition developers and the perceived audience? (I.e. is it short, clear sentences aimed at informing the unfamiliar public or paragraphs of scientific jargon only recognised by people with prior archaeological knowledge) 
In what context is the material identified as archaeology - as a self-contained scientific process? As indigenous material? As a contributing feature within a greater cultural setting?

Does the display make any reference to the processes in which archaeologists have processed this material and gained the information they have? (I.e. site surveys /excavations/ laboratory analysis)

How much archaeological material is featured in the display? Does it present archaeology as unique individual items or as assemblages examining the range of diversity and developmental trends?

To what level is the historical/ cultural/ (indigenous) content integrated with the archaeological event/ material to provide a fuller representation? Is it made clear how this has been established and supported?

Does the display at any time make reference to the popular misconceptions and imagery that people have for archaeology? Does it try to this correct this or simply use them as a way in which to draw the audience in?

To what level is there a recognition of different interpretations of the past archaeological/ local iwi / historians/ general public etc. or does one facet dominate?

Do any aspect of the exhibit prompt the audience with the opportunity to discuss or debate aspects of the display? I.e., questions left open or interpretation deliberately left vague. 


\section{References}

Allen, Harry. 2010. 'The Crisis in $21^{\text {st }}$ Century Heritage Management' In Phillips, Caroline and Allen, Harry (Eds). Bridging the Divide: Indigenous Communities and Archaeology into the $21^{\text {st }}$ Century. One World Archaeology Series 60. Left Coast Press Inc. USA. 157-180. Anderson, Atholl. 2014. 'Skinner, Henry Devenish'. The Dictionary of New Zealand Biography. Te Ara - the Encyclopedia of New Zealand. Last updated $18^{\text {th }}$ February 2014. http://www.TeAra.govt.nz/en/biographies/4s29/skinner-henry-devenish Accessed December 2014.

Auckland Museum 2014. Great Mercury Island Expedition; Learn About the Project.http://www.aucklandmuseum.com/collections-and-library/research-centre/researchprojects/great-mercury-island-expedition/learn-about-the-project Accessed December 2014.

Bartoy, Kevin M. 2012. 'Teaching Through Rather Than About: Education in the Context of Public Archaeology'. In Skeates, McDavid and Carman (Eds). The Oxford Handbook of Public Archaeology. Oxford University Press Inc. New York. 552-565.

Baxter, Alex. 2010. 'Exhibiting Archaeology: Archaeology and Museums'. Annual Review of Archaeology 39. 293-308.

Benton, Tim and Watson, Nicola J. 2010. 'Museum Practice and Heritage'. In West, Suzie (Ed) Understanding Global Heritage: Understanding Heritage in Practice. Manchester and New York: Manchester University Press.

Bintliff, John. 1993.'Why Indiana Jones is Smarter than the Post-Processualists'. Norwegian Archaeological Review 26(2). 91-100.

Buried Village of Te Wairoa. LivingHistoryhttp://www.buriedvillage.co.nz/living-history, Archaeological Sitehttp://www.buriedvillage.co.nz/archaeological-siteand Ways to Take the Tourhttp://www.buriedvillage.co.nz/Ways-to-take-the-tour. Accessed January 2015.

Butts, David. January 2015. Discussion with David Butts about historical aspects of archaeology in New Zealand museums. Personal Communication. 
Chan, Alexandra A. 2011. 'Translating Archaeology for the Public: Empowering and Engaging Museum Goers with the Past'. International Journal of Heritage Studies. Vol 17. No. 2. 169-189.

Clarke, Catherine. 2004. 'The Politics of Storytelling: Electronic Media in Archaeological Interpretation and Education'. Archaeological Pedagogies. Vol 36 (2). 275-286.

Clayworth, Peter. 2014. 'Anthropology and Archaeology - Professionals, Academics and Amateurs: 1920s to 1960s'.Te Ara - the Encyclopedia of New Zealand. Last updated $3^{\text {rd November 2014.http://www.TeAra.govt.nz/en/anthropology-and-archaeology/page- }}$ 4Accessed December 2014.

Davidson, Janet. 2004. 'Museums and the New Zealand Archaeological Association'. In Campbell, Matthew (Ed).Digging into History; 50 Years of the New Zealand Archaeological Association. Archaeology in New Zealand 47 (4). December 2004. University of Auckland Anthropology Department. 81-85.

--- 2013. 'Duff, Roger Shepherd'. The Dictionary of New Zealand Biography. Te Ara - the Encyclopedia of New Zealand. Last updated $7^{\text {th }}$ June 2013.

http:/www.TeAra.govt.nz/en/biographies/5d27/duff-roger-shepherd

Dell, R. K. $2013 a^{\prime}$ Falla, Robert Alexander'. The Dictionary of New Zealand Biography. Te Ara - the Encyclopedia of New Zealand. Last updated $17^{\text {th }}$ September 2013. http://www.TeAra.govt.nz/en/biographies/4f4/falla-robert-alexander

-- 2013b 'Oliver, Walter Reginald Brook'. The Dictionary of New Zealand Biography. Te Ara - the Encyclopedia of New Zealand. Last updated $11^{\text {th }}$ December 2013.http://www.TeAra.govt.nz/en/biographies/4o5/oliver-walter-reginald-brook

Derbet, Jolene. 2014. 'Hook 'em While They're Young: Using Enquiry Based Learning Workshops in Archaeology'. In Thomas, Suzie and Lea, Jonanne (Eds). Public Participation in Archaeology. Boydell and Brewer. Woolbridge.

Elliot, Jane. 2005. Using Narrative in Social Research. London; Thousand Oaks New Delhi: Sage.

Franklin, M Elaine and Moe, Jeane. 2012. 'A Vision for Archaeological Literacy'. In Skeates, Robin McDavid, Carol and Carman, John (Eds). The Oxford Handbook of Public Archaeology. Oxford University Press Inc. New York. 
Fung, Chris and Allen, Harry. 1984. 'Perceptions of the Past and New Zealand Archaeology'. NZAA Newsletter. Volume 27. No 4. December 1984. 209-220.

Gable, Eric and Handler, Richard. 2000. 'Public History; Private Memory: Notes from the Ethnography of Colonial Williamsburg, Virginia, USA'. Ethnos. Vol 65:2. 2000. 237-252.

Gomez Robbles, Lucia. 2011. 'Virtual Technologies (or not) for Dissemination'. E-Dialogos. Annual Journal on Research in Conservation and Cultural Heritage. August 2011. 34-45.

Hakiwai, Arapata T. 2005. 'The Search for Legitimacy: Museums in Aotearoa New Zealand A Maori Viewpoint'. In Corsane, Gerard. Heritage, Museums and Galleries; An Introductory Reader. London and New York: Routledge. 154-162.

Hall, Jenny and Swain, Hedley. 2000. 'Roman Boxes for London's Schools: An Outreach Service by the Museum of London”. In McManus, Paulette M Archaeological Displays and the Public Museology and Interpretations. Second Edition. Archetype Publications. University College London. 87-96.

Harsant, Wendy. 1987. 'The End of An Era: H. D. Skinner's Maori Gallery, Otago Museum'. NZAA Newsletter. Vol 30. No 1. March 1987.

Heritage New Zealand. 2014. A Journey Through the Waikato War. Education Resource Kit.http://www.hamiltonwaikato.com/the-waikato-war/downloads Accessed October 2014. Hocking, Elspeth. 2012. “"We Never Knew” The differences between museum history and academic history explored through an exhibition of the New Zealand Wars'. Unpublished dissertation. Museum and Heritage Studies. Victoria University of Wellington.

Hodge, Simon. 1995. 'The Public Understanding of Archaeology in New Zealand; Possible Reasons and Consequences'. Archaeology in New Zealand Newsletter. Vol 38. No 4. December 1995. 259-270.

Jones, Andrew. 1999. 'Archaeological Reconstruction and Education at the Jorvik Viking Centre and Archaeological Resource Centre, York'. In Stone, Peter G and Planel, Phillipe (Eds).The Constructed Past: Experimental Archaeology, Education and the Public. One World Archaeology Series 36. Routledge. UK. 258-268.

Livingstone, Roseanne. 1998. 'The History and Development of Foreign Ethnology Collections in the Museum of New Zealand Te Papa Tongarewa'. Tuhinga 10. 1-29. 
McCarthy, Conal. 2007. Exhibiting Maori: A History of Colonial Cultures of Display. Berg. Oxford. New York.

McQueen, H.C. 1942. 'Education in New Zealand Museums: An Account of Experiments assisted by the Carnegie Corporation of New York'. Studies in Education No 7. Whitcome and Tombs Ltd. Christchurch. New Zealand.

McDonald, Cathy. 2014. 'Archaeology in the School System: Powerful Partnerships - A Case Study of Challenges and Rewards for Archaeologists, Teachers and Students (Canada)'. In Thomas Suzie and Lea Jonanne (Eds). Public Participation in Archaeology. Boydell and Brewer, Woolbridge.

McFagen, Bruce. 1984. 'Museums and Communication; A Problem for the 80's'. AGMANZ News. Art Galleries and Museums Association of New Zealand.September1984. 6-8.

Merriman, Nick. 2000a. 'The Crisis of Representation in Archaeological Museums'. In Hatton, A and McManamon, Francis (Eds) Cultural Resource Management in Contemporary Society: Perspectives on Managing and Presenting the Past. One World Archaeology Series 33. Routledge. UK.

- - 2000b. 'Beyond the Glass Case: The Past, the Heritage and the Public'. Institute of Archaeology. University College, London. UK.

--- 2004. 'Involving the Public in Museum Archaeology'. In Merriman, Nick (Ed) Public Archaeology. Routledge. London and New York. 85-108.

-_- 2015. 'The Future of Collecting in 'Disciplinary' Museums: Interpretive, Thematic, Relational'. In McCarthy, Conal(Ed).Museum Practice Vol. 4.The International Handbooks of Museum Studies. General Editors: Macdonald, Sharon and Leahy, Helen Rees. Oxford \& Malden MA. Wiley Blackwell. 249-265.

Moussouri, Theano. 2014. 'From 'Telling' to 'Consulting': A Perspective on Museums and Modes of Public Engagement'. In Thomas, Suzie and Lea, Jonanne (Eds). Public Participation in Archaeology. Boydell and Brewer, Woolbridge.

Patton, Michael Quinn. 1990. Qualitative Evaluation and Research Methods. Thousand Oaks, CA. US: Sage Publications Inc. 
Phillips, Caroline. 2010. 'Working Together? Maori and Archaeologists in Aeoteroa/New Zealand Today'. In Phillips, Caroline and Allen, Harry (Eds). Bridging the Divide:

Indigenous Communities and Archaeology into the $21^{\text {st }}$ Century. One World Archaeology Series 60. Left Coast Press Inc. USA. 129-156.

Phillipps, Rebecca. 2015. Great Mercury Island/Ahuahu Dig Diaries. University of Auckland. http://digdiaries.ac.nz/fieldschool/Last updated February $14^{\text {th }} 2015$. Accessed February 2015.

Prickett, Nigel. 'The NZAA - A Short History'. In Campbell, Matthew, (Ed), Digging into History; 50 Years of the New Zealand Archaeological Association. Archaeology in New Zealand 47 (4) December 2004. University of Auckland Anthropology Department. 4-26.

Puke Ariki. 2015.History.http://pukeariki.com/Puke-Ariki/About-Us/HistoryAccessed January 2015.

Ramos, Maria and Duganne, David. 2000. 'Exploring Public Perceptions and Attitudes about Archaeology'. Society for American Archaeology. Harris Interactive Inc.

Rika Heke, Margaret. 2010. 'Archaeology and Indigeneity in Aotearoa/New Zealand: Why Do Maori Not Engage With Archaeology?’ In Phillips, Caroline and Allen Harry (eds) Bridging the Divide: Indigenous Communities and Archaeology into the $21^{\text {st }}$ Century. One World Archaeology Series 60. Left Coast Press Inc. USA. 197-212.

Shanks, Michael and Hodder, Ian. 1995.'Processual, Postprocessual, and Interpretive Archaeologies'. In Hodder et al. Interpreting Archaeology: Finding Meaning in the Past. Routledge, London.

Simmons, David. 1984. 'Anthropology in NZ Museums'. AGMANZ News. Art Galleries and Museums Association of New Zealand. Sept 1984. 2-4.

Swain, Hedley. 2007. An Introduction to Museum Archaeology. Cambridge University Press. New York.

Thistle, Paul C. 2012. 'Archaeology Excavation Simulation: Correcting the Emphasis'. Journal of Museum Education. Volume 37. No 2. Summer 2012. 67-78.

Trotter, Michael and McCulloch, Beverly. 1997. Digging Up the Past: New Zealand's Archaeological History. Penguin Books. Auckland, New Zealand. 
Walgren, Katty Hauptman and Svanberg, Fredrick. 2008. 'Public Archaeology as a Renewer of the Historical Museum'. Public Archaeology. Volume 7. No 4. Winter 2008. 241-258.

Winder, Virginia. 2005.Picture Provides Insight into Pa's Past.

http://pukeariki.com/Learning-Research/Taranaki-Research-Centre/Taranaki-

Stories/Taranaki-Story/id/335/title/picture-provides-insight-into-pas-past First Published January 28th 2005. Accessed September 2014.

\section{Unpublished Interviews}

All interviews conducted in person by the author, Brenden Shirley, unless noted.

$6^{\text {th }}$ August 2014 - Michelle Horwood (Wellington)

$27^{\text {th }}$ August 2014 - Pam Bain (Wellington)

$29^{\text {th }}$ August $2014-$ Amy Hobbs (Wellington)

$1^{\text {st }}$ and $5^{\text {th }}$ September 2014 - Glen Skipper (New Plymouth)

$2^{\text {nd }}$ September 2014 - Elspeth Hocking (New Plymouth)

$3^{\text {rd }}$ September 2014 - Channelle Carrick (New Plymouth)

$3^{\text {rd }}$ and $5^{\text {th }}$ September 2014 - Keri Elvin (New Plymouth)

$4^{\text {th }}$ September 2014 -Gary Bastin (New Plymouth)

$4^{\text {th }}$ September 2014 - Andrew Moffatt (New Plymouth)

$17^{\text {th }}$ September 2014 - Dougal Austin (Wellington)

$23^{\text {rd }}$ September 2014 - Peter Adds (Wellington)

$23^{\text {rd }}$ September 2014 - Kelvin Day (Wellington \{phone interview $\}$ )

$30^{\text {th }}$ September 2014 -Janet Davidson (Wellington)

$21^{\text {st }}$ October 2014 - Louise Furey (Wellington \{phone interview\}) 
